\title{
The NASA In-Space Propulsion Technology Project's Current Products and Future Directions
}

\author{
David J. Anderson ${ }^{1}$ (216-433-8709, David.J.Anderson@nasa.gov) \\ John Dankanich² (216-433-5356, John.Dankanich@nasa.gov) \\ Michelle M. Munk ${ }^{3}$ (757-864-2314, Michelle.M.Munk@nasa.gov) \\ Eric Pencil1 (216-977-7433, Eric.J.Pencil@nasa.gov) \\ Larry Liou ${ }^{1}$ (216-977-7433, Larry.C.Liou@nasa.gov) \\ ${ }^{1}$ NASA Glenn Research Center, 21000 Brookpark Road, Cleveland, OH 44135 \\ ${ }^{2}$ Gray Research, Inc., Cleveland, OH 44135 \\ ${ }^{3}$ NASA Langley Research Center, Hampton, VA 23681
}

Abstract-Since its inception in 2001, the objective of the In-Space ${ }^{12}$ Propulsion Technology (ISPT) project has been developing and delivering in-space propulsion technologies that enable or enhance NASA robotic science missions. These in-space propulsion technologies are applicable, and potentially enabling for future NASA flagship and sample return missions currently under consideration, as well as having broad applicability to future Discovery and New Frontiers mission solicitations. This paper provides status of the technology development, applicability, and availability of in-space propulsion technologies that recently completed, or will be completing within the next year, their technology development and are ready for infusion into missions. The paper also describes the ISPT project's future focus on propulsion for sample return missions.

The ISPT technologies completing their development are: 1) the high-temperature Advanced Material Bipropellant Rocket (AMBR) engine providing higher performance for lower cost; 2) NASA's Evolutionary Xenon Thruster (NEXT) ion propulsion system, a $0.6-7 \mathrm{~kW}$ throttle-able gridded ion system; and 3) aerocapture technologies which include thermal protection system (TPS) materials and structures, guidance, navigation, and control (GN\&C) models of blunt-body rigid aeroshells; and atmospheric and aerothermal effect models. The future technology development areas for ISPT are: 1) Planetary Ascent Vehicles (PAV); 2) multi-mission technologies for Earth Entry Vehicles (MMEEV) needed for sample return missions from many different destinations; 3 ) propulsion for Earth Return Vehicles (ERV) and transfer stages, and electric propulsion for sample return and low cost missions; 4) advanced propulsion technologies for sample return; and 5) Systems/Mission Analysis focused on sample return propulsion.

${ }^{1}$ U.S. Government work not protected by U.S. copyright

${ }^{2}$ IEEEAC paper\#1078, Version 4, Updated 2009:12:28
TABLE OF CONTENTS

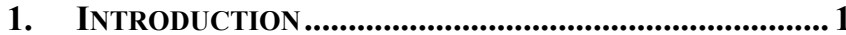

2. TECHNOLOGY DEVELOPMENT OVERVIEW ................. 2

3. Advanced Chemical Propulsion........................... 3

4. AEROCAPTURE …........................................................... 5

5. EleCtric PRopulsion ............................................. 8

6. SAMPLE RETURN PROPULSION ....................................12

7. Planetary ASCENT Vehicle ................................... 14

8. MUlti-MisSiOn EaRTh ENTRY VEHICle .................15

9. SYSTEMS/MISSION ANALYSIS ....................................... 16

10. TECHNOLOGY INFUSION ............................................ 17

11. Future Plans ANd CoNCluSIONS ............................ 17

REFERENCES.................................................................... 18

BIOGRAPHY .................................................................... 19

\section{INTRODUCTION}

NASA's Science Mission Directorate (SMD) missions seek to answer important science questions about our planet, the Solar System and beyond. Since 2001, the In-Space Propulsion Technology (ISPT) project has been developing and delivering in-space propulsion technologies that will enable and/or benefit near and mid-term NASA robotic science missions by significantly reducing cost, mass, and/or travel times. ISPT technologies will help deliver spacecraft to SMD's destinations of interest.

To meet NASA's future mission needs, the goal of the ISPT project has been the development of new enabling propulsion technologies that cannot be reasonably achieved within the cost or schedule constraints of mission development timelines, specifically achieving technology readiness level (TRL) 6 prior to preliminary design review (PDR). Since the ISPT goal is to develop products that realize near-term and mid-term benefits, ISPT primarily focuses on technologies in the mid TRL range (TRL 3-6+ range) that have a reasonable chance of reaching maturity in 4-6 years provided adequate development resources. The project strongly emphasizes developing propulsion products for NASA flight missions. 
ISPT emphasizes technology development with mission pull. Initially the ISPT goal was to develop technologies for Flagship missions. This goal led to the priorities of aerocapture (the use of aerodynamic drag for orbit capture) and electric propulsion. In 2006, the Solar System Exploration (SSE) Roadmap [1] identified technology development needs for Solar System exploration, and described transportation technologies as highest priority (new developments are required for all or most roadmap missions). According to the SSE Roadmap, the highest priority propulsion technologies are electric propulsion and aerocapture. The SSE Road map specifically stated that "Aerocapture technologies could enable two proposed Flagship missions, and solar electric propulsion could be strongly enhancing for most missions. These technologies provide rapid access, or increased mass, to the outer Solar System."[1] Electric propulsion and aerocapture are suited for enabling significant science return for the outer planetary moons under investigation. The ISPT technologies were quantified to allow greater science return with reduced travel times. The ISPT priorities and products are tied closely to the science roadmaps, the SMD's science plan, and the decadal surveys. Excerpts from the science community are discussed in more detail in Ref. [2].

ISPT implements the project through task agreements with NASA centers, contracts with industry, and via grants with academic institutions. Implementing NASA centers include Ames Research Center (ARC), Dryden Flight Research Center (DRFC), Glenn Research Center (GRC), Goddard Space Flight Center (GSFC), Jet Propulsion Laboratory (JPL), Johnson Space Center (JSC), Langley Research Center (LaRC), and the Marshall Space Flight Center (MSFC). There are also numerous industry partners in the development of the ISPT products. It is one of ISPT's objectives that all ISPT products be ultimately manufactured by industry and made equally available to all potential users for missions and proposals. From 2001 to 2006, the ISPT project office was located at MSFC, where it was initiated and managed. Since late 2006, the ISPT project office has been located at GRC where it has managed the ISPT project for Science Mission Directorate.

This paper provides a brief overview of the ISPT project with development status, near-term mission benefits, applicability, and availability of in-space propulsion technologies in the areas of aerocapture, electric propulsion, advanced chemical propulsion, planetary ascent vehicles, Earth return vehicles, other advanced propulsion technologies, and mission/systems analysis tools. These inspace propulsion technologies are applicable, and potentially enabling for future NASA flagship and sample return missions currently under consideration, as well as having broad applicability to future Discovery and New Frontiers mission solicitations.

\section{TECHNOLOGY DEVELOPMENT OVERVIEW}

The ISPT project is currently completing the development efforts in four technology areas. These include Advanced Chemical Propulsion, Aerocapture, Electric Propulsion, and Systems/Mission Analysis. The primary technology development in advanced chemical propulsion was the development of the Advanced Material Bi-propellant Rocket (AMBR) engine, which completed its developmental activities in 2009. Advanced chemical propulsion investments included the demonstration of active-mixtureratio-control and lightweight tank technology. The advanced chemical propulsion technologies have an opportunity for rapid-technology infusion with minimal risk and broad mission applicability.

Aerocapture technology developments result in better models for: 1) guidance, navigation, and control (GN\&C) of blunt body rigid aeroshells, 2) atmosphere models for Earth, Titan, Mars and Venus, and 3) models for aerothermal effects. In addition to enhancing the technology readiness level (TRL) of rigid aeroshells, improvements were made in understanding and applying inflatable aerocapture concepts. Aerocapture technology was a contender for flight validation on NASA's New Millennium ST9 mission.

Electric propulsion (EP) technology development activities are focusing on completing NASA's Evolutionary Xenon Thruster (NEXT) ion propulsion system. The NEXT system was selected under a competitive solicitation for an EP system applicable to a Flagship mission. NEXT is a 0.6-7$\mathrm{kW}$ throttle-able gridded ion system suitable for future Discovery, New Frontiers, and flagship missions. At a subcomponent level, ISPT is pursuing the development of a lightweight reliable xenon flow control system as well as standardized EP subcomponent designs. The ISPT project continues the development of other electric propulsion products, such as the High-Voltage Hall Accelerator (HIVHAC) thruster. The HIVHAC thruster is designed as a low cost, highly reliable thruster suited for cost-capped NASA Discovery-class missions.

The systems analysis technology area performed numerous mission and system studies to guide technology investments and quantify the return on investment. Recent focus of the systems analysis area has been on developing tools to assist technology infusion. Tool development has included the development of low-thrust trajectory tools (LTTT), a suite of computer programs optimized for developing mission trajectories using EP, and an aerocapture quicklook tool.

In 2009, ISPT was tasked to start development of propulsion technologies that would enable future sample return missions. Sample return missions could be quite varied, from collecting and bringing back samples of comets or asteroids, to soil, rocks, or atmosphere from planets or moons. Given this new focus, the future technology development areas for ISPT are: 
(1) Sample Return Propulsion, which includes:

(a) Electric propulsion for sample return and low cost Discovery-class missions

(b) Propulsion systems for Earth Return Vehicles (ERV) including transfer stages to the destination

(c) Low TRL advanced propulsion technologies

(2) Planetary Ascent Vehicles (PAV), with a Mars Ascent Vehicle (MAV) being the initial development

(3) Multi-mission technologies for Earth Entry Vehicles (MMEEV)

(4) Systems/Mission Analysis that focuses on sample return propulsion

The work on HIVHAC completes the thruster development in FY2010 and then transitions into developing a HIVHAC system under future Electric Propulsion for sample return (ERV and transfer stages) and low-cost missions. Previous work on the lightweight propellant-tanks will continue under advanced propulsion technologies for sample return with direct applicability to a Mars Sample Return (MSR) mission and with general applicability to all future planetary spacecraft. The Aerocapture efforts will merge with previous work related to Earth Entry Vehicles and transitions into the future multi-mission technologies for Earth Entry Vehicles (MMEEV). The Planetary Ascent Vehicles (PAV)/ Mars Ascent Vehicle (MAV) is a new development area to ISPT but builds upon and leverages the past MAV analysis and technology developments from the Mars Technology Program (MTP) and previous MSR studies.

\section{Advanced Chemical Propulsion}

ISPT's approach to the development of chemical propulsion technologies was the evolution of subcomponent technologies that still offered significant performance improvements. The main area of investment focused on items that would provide performance benefit with minimal risk with respect to the technology being incorporated into future fight systems. Current technology investments include the AMBR high temperature bi-propellant thruster (Figure 1), and tasks to improve mixture ratio control, and reliable lightweight propellant tanks.

The primary investment within the advanced chemical propulsion technology area was the Advanced Materials Bipropellant Rocket (AMBR) engine, which was awarded, through a competitive process, to Aerojet Corporation in FY2006. The AMBR engine is a high temperature thruster addressing the cost and manufacturability challenges by using iridium coated rhenium chambers. It expands the operating environment to higher temperatures with the goal of achieving a seven-second increase in Specific Impulse $\left(\mathrm{I}_{\mathrm{sp}}\right)$ for $\mathrm{NTO} / \mathrm{N}_{2} \mathrm{H}_{4}$. The current program included the manufacture and hot-fire tests of prototype engine(s) demonstrating increased performance and validating new manufacturing techniques. Additional information is found in the AMBR information summary in the New Frontiers and Discovery program libraries. $[3,4,27]$

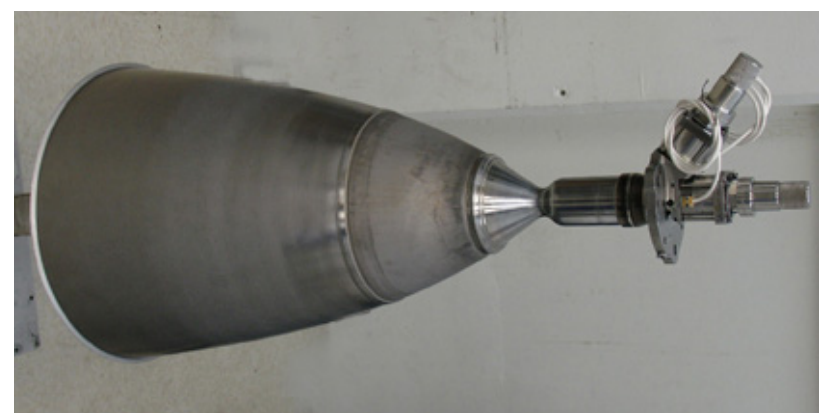

Figure 1 - AMBR test article

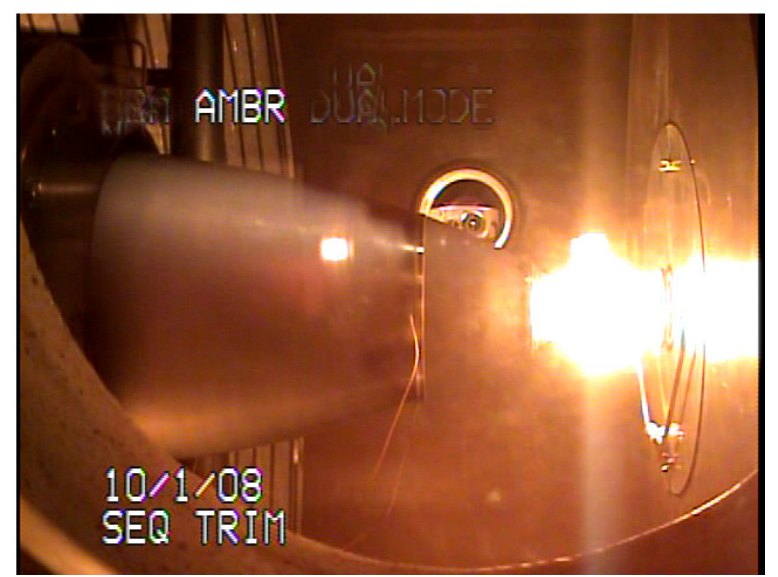

Figure 2 - AMBR hot fire performance test

Performance testing was conducted on the AMBR engine in October 2008 (Figure 2) and February 2009, and long duration testing in June 2009. The results show an $I_{\text {sp }}$ of 333 seconds- the highest ever achieved for hydrazine/NTO propellant combination (Figure 3). This result represents a five second $\mathrm{I}_{\mathrm{sp}}$ gain over the HiPAT engine, at a thrust of $140 \mathrm{lbf}$, mixture ratio of 1.1, chamber pressure of 195 psia, and oxidizer inlet pressure of 250 psia. While these numbers differ from the original goal of 335 seconds $I_{s p}, 200 \mathrm{lbf}$ thrust, mixture ratio of 1.2, and an inlet pressure of 400 psia, the single-iteration results are very encouraging. The test results show that the engine, as currently operating, can benefit many space applications. Typically, planetary and commercial spacecraft operate at pressures more comparable to the lower 250 psia propellant inlet pressure obtained in the test. To improve the readiness for flight infusion, AMBR completed environmental tests including vibration, shock, and life-firing tests. Although desirable but not currently funded, a possible next step would be to improve the combustion chamber film cooling in order to operate closer to its original performance target. 


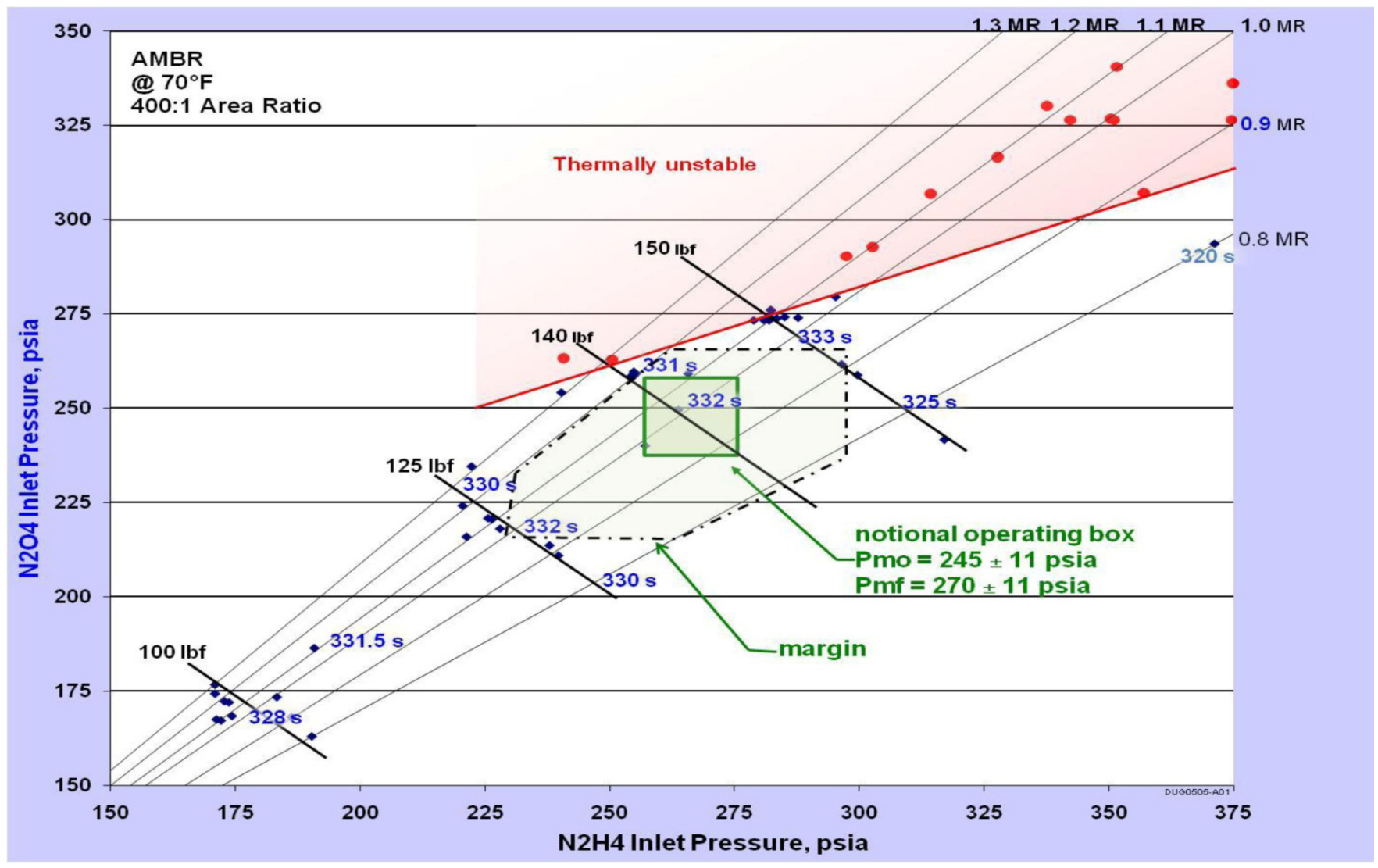

Figure 3 - Notional operating box for AMBR engine

The AMBR engine development [5] benefits missions with large propulsion maneuvers through the reduction of wet mass. The expectation for the AMBR engine is to have a 30 percent cost reduction in the combustion chamber manufacturing with an increase in performance. The mission mass benefits are dependent on the missionrequired $\Delta \mathrm{V}$, but are approximately the size of scientific instrument packages flown on previous missions. Figure 4 shows the potential reduction in system mass, which could result in increased payload or margins, due to the increased specific power for multiple missions. These early study results were based on the initial AMBR target performance targets of 335 seconds Isp and $200 \mathrm{lbf}$ thrust. If one uses target performance data and corresponding benefit analysis, the approximate mass benefit can be determined from Figure 4. The number of thrusters needed in a mission like Cassini, having a higher thrust engine reducing complexity, is reduced The system would deliver additional mass, over $50 \mathrm{~kg}$; which equates to a potential increase in scientific payload by 100 percent.

Mixture Ratio (MR) control either reduces the residuals propellants carried or allows for additional extended mission operation otherwise lost due to an imbalance in the oxidizerto-fuel ratio experienced during operation. Small investments were made to characterize balance flow meters, validate MR control to maximize precision, and determine the potential benefits of MR control. Two hot-fire tests of the system hardware (the Balanced Flow Meters) were held during the AMBR testing and results are being compiled.

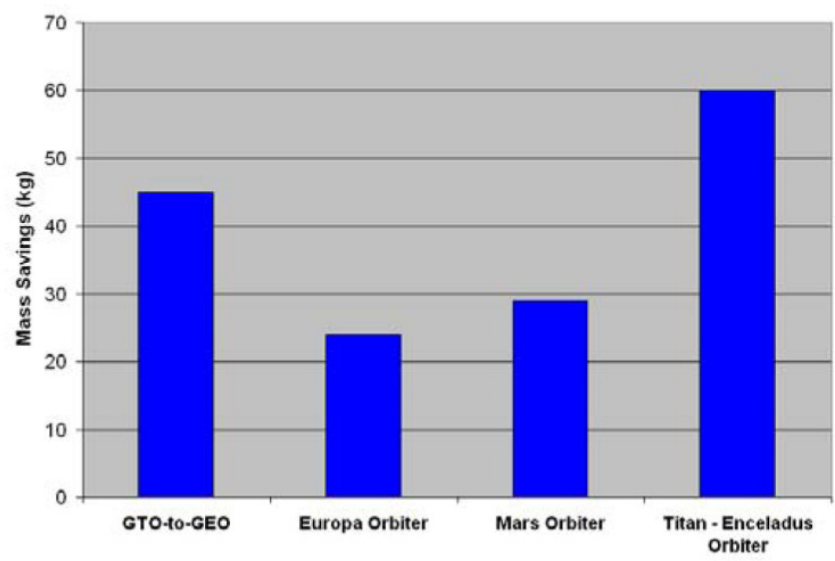

Figure 4 - Mass benefits from the AMBR engine

The need for mixture ratio control (MRC) stems from the propulsion system margin that must be carried due to MR uncertainty. It is common for spacecraft with bi-propellant propulsion systems to reach end-of-life with residual oxidizer or fuel. Controlling the mixture ratio allows for either reduced residuals at launch, decreased mission risk by increasing propellant margin, or increased mission duration. Because the savings are directly proportional to the amount of propellant consumed, benefits are more significant on 
missions requiring large $\Delta \mathrm{V}$ maneuvers. Typically, those missions already use bi-propellant systems.

Investments were made to evaluate manufacturing techniques for thin liner composite overwrap pressure vessels (COPV). The task evaluated liner bonding and welding techniques. The improved fabrication processes meet manufacturing recommendations and standards to minimize risk and increase yields for COPVs. This activity worked directly with members of NASA's COPV working group, who implement the standard processes in future COPV efforts.

The use of lightweight tanks produces a direct savings by reducing the propulsion system dry mass. Mass benefits approximate 2.5 percent of the propellant mass, or net tank mass savings of 50 percent over state-of-the-art titanium tanks.

The mission benefits in advanced chemical propulsion are synergistic, and the cumulative effects have tremendous potential. The infusion of the individual subsystems separately provides reduced risk, or combined provides considerable payload mass benefits. Ref. 26 has a thorough description of the complete Advanced Chemical Propulsion effort that was concluded in 2009.

\section{Aerocapture}

Aerocapture is the process of entering the atmosphere of a target body to practically eliminate the chemical propulsion requirements of orbit capture. Aerocapture is the next step beyond aerobraking, which relies on multiple passes high in the atmosphere using the spacecraft's drag to reduce orbital energy. Aerobraking has been used at Mars on multiple orbiter missions. Aerocapture, illustrated in Figure 5, maximizes the benefit from the atmosphere by capturing in a single pass. Aerocapture represents a major advance over aerobraking techniques, by generating more drag by flying at a lower altitude where the atmosphere is denser. Keys to successful aerocapture are a lightweight thermal protection system and structure, accurate arrival state knowledge, validated atmospheric models, sufficient vehicle control authority (i.e. lift-to-drag ratio), and robust guidance during the maneuver.

The execution of the aerocapture maneuver itself is what enables the great mass savings over other orbital insertion methods. If the hardware subsystems are not mass efficient, or if performance is so poor that additional propellant is needed to adjust the final orbit, the benefits are significantly reduced. ISPT efforts in aerocapture subsystem technologies are focused on improving the efficiency and number of suitable alternatives for aeroshell structures and ablative thermal protection systems (TPS). These include development of families of low and medium density (14-36 $\left.\mathrm{lbs} / \mathrm{ft}^{3}\right)$ TPS, and the related sensors, development of a carbon-carbon rib-stiffened rigid aeroshell, and high temperature honeycomb structures and adhesives.
Development occurred on inflatable decelerators through concept definition and initial design and testing of several inflatable decelerator candidates. Finally, progress is being made through improvement of models for atmospheres, aerothermal effects, and algorithms and testing of a flightlike guidance, navigation and control (GN\&C) system.

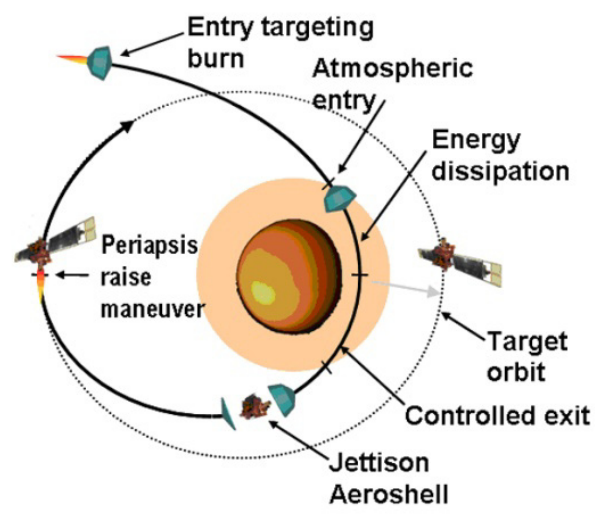

Figure 5 - Illustration of the aerocapture maneuver

Aerocapture enables rapid access to orbital missions at the outer planets and is enabling for two of the potential flagship missions in the last Roadmap-Titan Explorer and Neptune-Triton Explorer. For targets in the outer Solar System, aerocapture technology would reduce the trip time and deliver a larger payload mass, enabling these missions to be implemented with the current generation of heavy lift launch vehicles. The SSE Roadmap recommends "Aerocapture technologies and flight validation are a high priority to solar system exploration."[1] The March 2008 OPAG meeting minutes recommends that "Aerocapture is a key enabling technology for the outer solar system, particularly at Titan, and some gas giant planets"[15]

Titan Explorer could be the first to use this technology in a Flagship mission. Because of the deep atmosphere, largescale height, and modest entry velocities, Titan is an attractive target for the use of aerocapture. For a potential Neptune-Triton Explorer (NTE) mission, aerocapture enables transit from Earth to Neptune in less than ten years. Because of the much higher entry velocity and a narrow entry corridor, Neptune is a more challenging target for aerocapture than Titan.

The majority of investment in aerocapture technology occurred in advancing the TRL of efficient rigid aeroshell systems. A family of low-density TPS materials carrying the identifier "SRAM" was developed under a competitively awarded contract with Applied Research Associates (ARA). These have a density range between $14 \mathrm{lb} / \mathrm{ft}^{3}$ and $24 \mathrm{lb} / \mathrm{ft}^{3}$ with the variable performance achieved by adjusting the ratios of constituent elements. These are applicable for heating rates up to $150 \mathrm{~W} / \mathrm{cm}^{2}$ and $500 \mathrm{~W} / \mathrm{cm}^{2}$ respectively. 
They could be used on missions with destinations to small bodies such as Titan and Mars. The SRAM family of ablators was tested in both arcjet and solar tower facilities at the coupon level; one-ft and two-ft square flat panels, and on a one meter, 70 degree, blunt body aeroshell structure; shown in Figure 6. Another ARA family of low-to-medium density TPS systems (PhenCarb) is phenolic-based, ranges in density between 20 and $36 \mathrm{lb} / \mathrm{ft}^{3}$, and is applicable for heating rates between 200 and $1,500 \mathrm{~W} / \mathrm{cm}^{2}$.

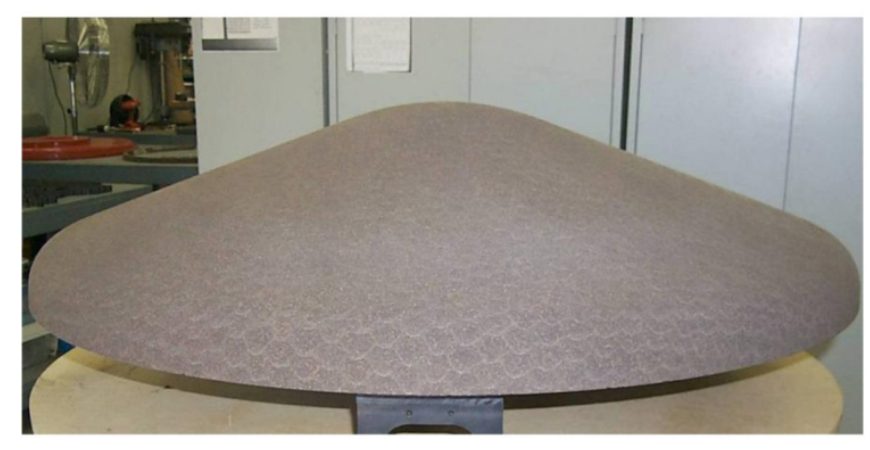

Figure 6 - 1.0-meter aeroshell

In support of the rigid TPS system, ISPT funded testing of higher temperature adhesives and development of higher temperature composite structures effectively increasing the allowable bond-line temperature from $250^{\circ} \mathrm{C}$ to $325^{\circ}$ or $400^{\circ} \mathrm{C}$ depending on the adhesive and composite construction. This work was performed by ATK, in the division formerly known as Composite Optics. Sensors that measure aeroshell recession with accuracy of hundredths of millimeters were developed at NASA's Ames Research Center and are currently planned for use on the Mars Science Laboratory (MSL) mission. Instrumenting entry systems to gather flight data is of primary importance to understand the environments and resulting vehicle requirements for future missions.

Another advancement, enabled by ISPT funding, is the development of a Carbon-Carbon aeroshell that is rib stiffened, reducing the need for an additional structure system. The reduced mass of the structure, coupled with low-density insulation on the side of the shell, results in a 30 percent mass density improvement over the same size Genesis-like aeroshell. When this system was mechanically tested to levels that are representative of expected aerocapture loading environments, the system response compared within 10 percent to the finite element model, validating that model for use in predicting system response to other environments. This effort was competitively awarded and completed in early 2007 by Lockheed Martin and their partner Carbon-Carbon Advanced Technologies (C-CAT), and resulted in a TRL-6 product applicable for use in multiple NASA science missions.

Ames Research Center developed and enhanced models that predict the entry thermal environments for aerocapture at Titan, Mars, Venus, and Neptune. In some cases, previous heating estimates were overly conservative because of the lack of resources available to produce validation data or to develop more complicated analysis methods. Coupled models updated with the most current Cassini data reveal, that aerocapture at Titan will load the TPS system at less than $20 \mathrm{~W} / \mathrm{cm}^{2}$ verses prior predictions of $150-300 \mathrm{~W} / \mathrm{cm}^{2}$. Through multiple years of concentrated effort, researchers funded by ISPT made modeling improvements that benefit all future entry missions. ISPT funds supported the generation or update of engineering level atmospheric models for all primary aerocapture destinations except Earth.

Inflatable decelerator concepts promise additional mass savings beyond expectations from rigid aeroshell systems. The ISPT team considered several competing concepts to understand and address the technical challenges with these types of systems. Ball Aerospace and Lockheed Martin teams developed first order fluid-structure models to understand the requirements for thin film materials and adhesives. Preliminary testing was conducted in concept preparation for trailing toroidal, clamped afterbody, and inflatable forebody decelerators. ISPT funded team members continue their inflatable decelerator efforts under NASA's Aeronautics Research Mission Directorate (ARMD).

ISPT developed a rigorous, peer-reviewed plan as part of the ST9 New Millennium Proposal to take the ablative aerocapture system to a TRL 6 by FY09. Though the ST9 flight opportunity was cancelled, ISPT is still following the ground development program preparing the technology for a flight demo or first mission infusion. A 2.65-m diameter high-temperature aeroshell, with ARA's SRAM TPS, is being built as a manufacturing demonstration, to be completed by early 2010 .

Future plans are to complete the ground development of the ablative aeroshell system. This includes the improvement of aerothermal models, atmospheric models and real-time testing a GN\&C algorithm with flight software and hardware in the loop. Completion of the GN\&C work is expected to be in CY09. Additional information on aerocapture technology developments can be found in the Discovery program library [27] and in Ref. [16-21]

The use of aerocapture was studied extensively, most notably for use at Titan, Neptune, Venus and Mars. Figure 7 shows the anticipated increases in delivered mass. The largest mass benefit from aerocapture was observed for Neptune, low Jupiter orbits, followed by Titan, Uranus, Venus, and then only marginal gains for Mars (the mass benefit is directly correlated to the amount of velocity change required for each mission). Alternatively, cost benefits are realized for multiple missions. When the overall system mass is reduced, the mission can utilize a smaller launch vehicle, saving tens of millions of dollars. Detailed mission assessment results are in Ref. [22-24]. 
The mission mass benefits to Mars are expected to be about 5-15 percent, depending on the scale of the spacecraft. These benefits can be enabling. A multi-center team from ARC, JPL, JSC, LaRC, and MSFC conducted detailed mission and cost analyses for various Mars opportunities. An opposition-class sample return mission can be enabled in less than two years using aerocapture. Aerocapture enhances conjunction-class sample-return missions and large Mars orbiters. No new technology gaps were identified that would delay aerocapture implementation on such a mission.

\begin{tabular}{|c|c|c|c|c|c|c|}
\hline Mission & Science Orbit & $\begin{array}{c}\text { Nominal } \\
\text { Orbit } \\
\text { Insertion } \\
\Delta \mathrm{V}, \mathrm{km} / \mathrm{s}\end{array}$ & $\begin{array}{l}\text { Best A/C } \\
\text { Mass, kg }\end{array}$ & $\begin{array}{c}\text { Best } \\
\text { non A/C } \\
\text { Mass, kg }\end{array}$ & $\begin{array}{c}\text { A/C \% } \\
\text { Increase }\end{array}$ & $\begin{array}{c}\text { Best non A/C } \\
\text { Option }\end{array}$ \\
\hline Venus V1 & 300 km circ & 4.6 & 5078 & 2834 & 79 & All-SEP \\
\hline Venus V2 & $8500 \times 300 \mathrm{~km}$ & 3.3 & 5078 & 3542 & 43 & All-SEP \\
\hline Mars M1 & $300 \mathrm{~km}$ & 2.4 & 5232 & 4556 & 15 & Aerobraking \\
\hline Mars M2 & -1 Sol ellipse & 1.2 & 5232 & 4983 & 5 & Chem 370 \\
\hline Jupiter J1 & 2000 km circ & 17.0 & 2262 & $<0$ & Infinite & $\mathrm{N} / \mathrm{A}$ \\
\hline Jupiter j2 & Callisto ellipse & 1.4 & 2262 & 4628 & -51 & Chem 370 \\
\hline Saturn S1 & 120,000 km circ & 8.0 & 494 & $<0$ & Infinite & $N / A$ \\
\hline Titan T1 & 1700 km circ & 4.4 & 2630 & 691 & 280 & Chem 370 \\
\hline Uranus U1 & Titania ellipse & 4.5 & 1966 & 618 & 218 & Chem 370 \\
\hline Neptune N1 & Triton ellipse & 6.0 & 1680 & 180 & 832 & Chem 370 \\
\hline
\end{tabular}

Figure 7 - Aerocapture benefits for various targets.

Venus was studied extensively to identify any needs for TPS, guidance, atmospheric or heating models. Detailed analyses evaluated the potential for aerocapture for a Venus Discovery class mission. Aerocapture delivered more than 80 percent additional mass over aerobraking and more than 600 percent over a chemical insertion. Aerocapture reduces Deep Space Network (DSN) time by 121 days. No critical technology gaps were identified for aerocapture at Venus, but investments in TPS are recommended for achieving maximum mass benefits.

Titan continues to be of considerable scientific interest following the success of Cassini/Huygens. Because of its atmospheric structure, it is an ideal candidate for aerocapture. The Outer Planets Flagship (OPF) study considered aerocapture within the baseline mission concept since aerocapture has the capability to delivery more than double the scientific payload of the chemical alternative. Aerocapture may play a key role in accomplishing a reduced Titan mission for a less-than-Flagship budget.

Aerocapture was proven repeatedly to be an enabling or strongly enhancing technology for several atmospheric targets. The ISPT project team continues to develop aerocapture technologies in preparation for a flight demonstration. Rapid aerocapture analysis tools are being developed and made available. The TPS materials developed through ISPT enhance a wide range of missions by reducing the mass of entry vehicles. Figure 8 illustrates the remaining gaps required for technology infusion. All of the component subsystems are currently at or funded to reach TRL 6 in the next year for multiple targets of interest. These subsystems can be applied to small-scale entry missions, even if the aerocapture maneuver is not utilized.

Aerocapture cannot reach TRL 6 for the system without space flight validation, and it is impossible to match the flight environment in ground facilities. Missions must be willing to accept the small risk of this shortfall, to realize the tremendous benefits of the technology. If they are not willing, Aerocapture will need to be validated in space before its first mission infusion. A space flight validation is expensive, but the costs will be recouped very quickly. The validation immediately reduces the risk to the first user and validates the maneuver for application to multiple, potentially lower-cost, missions to Titan, Mars, Venus, and Earth. Moreover, once Aerocapture is proven a reliable tool, it is anticipated that entirely new mission possibilities will open up. 

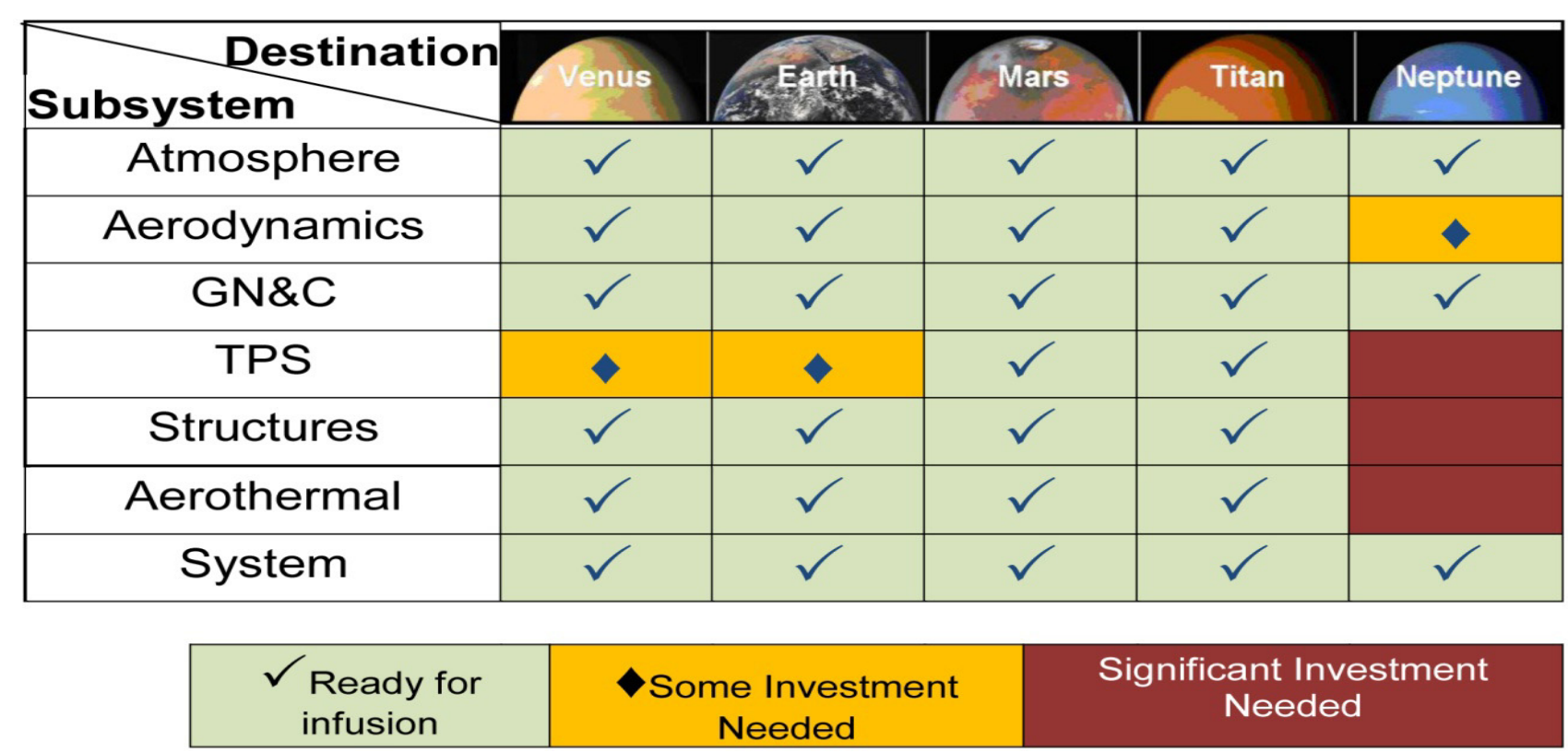

Figure 8 - Aerocapture readiness for various targets.

\section{Electric Propulsion}

Solar Electric Propulsion (SEP) enables missions requiring large in-space velocity changes over time. SEP has applications to rendezvous and sample return missions to small bodies and fast trajectories towards the outer planets. This is particularly relevant to the Saturn-Titan-Enceladus and the Neptune-Triton missions. In particular, the TitanSaturn System mission demonstrated that improvements to mass, trip-time, and launch flexibility provided by SEP resulted in significant benefits to the mission.

Major science missions are demonstrating the growing acceptance of SEP for interplanetary transportation, including missions such as Dawn, SMART-1, and Hayabusa. Fully exploiting the low-thrust SEP technology requires trajectory design methods to cope with continuous thrusting rather than executing a few large thruster maneuvers at optimal points in the trajectory.

Significant improvements in the efficiency and performance of SEP are underway. The resulting systems may provide substantial benefits to the SSE Roadmap's planned missions to small bodies and the inner planets. When coupled with aerocapture (rapid aerodynamic braking within a planetary atmosphere), SEP enables rapid and cost-effective delivery of orbital payloads to the outer Solar System. The SSE Roadmap recommends "SEP technologies should be fully integrated with missions planning aerocapture.’[1]

Electric propulsion is both an enabling and enhancing technology for reaching a wide range of targets. The high specific impulse, or efficiency of electric propulsion system, allows direct trajectories to multiple targets that are chemically infeasible. The technology allows for rendezvous missions in place of fly-bys, and as planned in the Dawn mission can enable multiple destinations.

In the current discussions of comparing ground-based test facilities to spaced-based test facilities, there needs to be a compelling reason to test in space to justify the high costs associated with space operations. There were several assessments which have already examined the benefits and limitations of using the International Space Station (ISS) for electric propulsion research. Limitations regarding available power for EP thruster operation is a known problem, and limits thruster operation to a few kilowatts. One benefit of space-based test facilities is the "infinite" pumping speed due to expansive vacuum volume. However, there is adequate pumping speed in ground-based facilities to address development needs for all ISPT products. Disruptions caused by microgravity research environment requirements, ISS operation, and cargo resupply limits total in-orbit operation time for thruster demonstrations. These restrictions require EP development programs to use ground-based facilities to mature technologies for first missions. Overall the marginal improvements to thruster environments on space-based facilities are not sufficient to justify the higher development costs and to overcome the severe technical limitations of available power and thruster operation.

This technology offers major performance gains, only moderate development risk, and has significant impact on the capabilities of new missions. Current plans include completion of the NASA's Evolutionary Xenon Thruster (NEXT) Ion Propulsion System target at Flagship, New Frontiers and demanding Discovery missions under NASA's In-Space Propulsion Technology Program. It uses a "Standard Architecture" design approach, use of already 
flight qualified components for electric propulsion subsystems, and an Advanced Xenon Feed System.

The GRC-led NEXT project was competitively selected to develop a nominal $40-\mathrm{cm}$ gridded-ion electric propulsion system.[6,7] The objectives of this development were to improve upon the state-of-art NASA Solar Electric Propulsion Technology Readiness (NSTAR) system flown on Deep Space-1 to enable flagship class missions by achieving:

- lower specific mass

- $\quad$ higher $\mathrm{I}_{\mathrm{sp}}$ (4050 s)

- $\quad$ greater throughput (current estimates exceed 700 $\mathrm{kg}$ of xenon),

- $\quad$ greater power handling capability $(6.9 \mathrm{~kW})$, thrust $(240 \mathrm{mN})$, and throttle range (12:1).

The ion propulsion system components developed under the NEXT task include the ion thruster, the power-processing unit (PPU), the feed system, and a gimbal mechanism. The NEXT project is developing prototype-model (PM) fidelity thrusters through Aerojet Corporation. In addition to the technical goals, the project has the goal of transitioning thruster-manufacturing capability with predictable yields to an industrial source. A prototype model NEXT thruster passed qualification level environmental testing (Figure 9). The prototype model thruster completed a short duration test in which overall ion engine performance was steady with no indication of performance degradation. As of December 31, 2009 the thruster achieved over $450 \mathrm{~kg}$ xenon throughput and $>26,450$ hours at multiple throttle conditions. The NEXT wear test demonstrated the largest total impulse ever achieved by a gridded-ion thruster. ISPT funding for the thruster life test continues through FY12 with the aim of demonstrating up to $750 \mathrm{~kg}$ of xenon throughput. The resulting total impulse capability is shown in Figure 10.

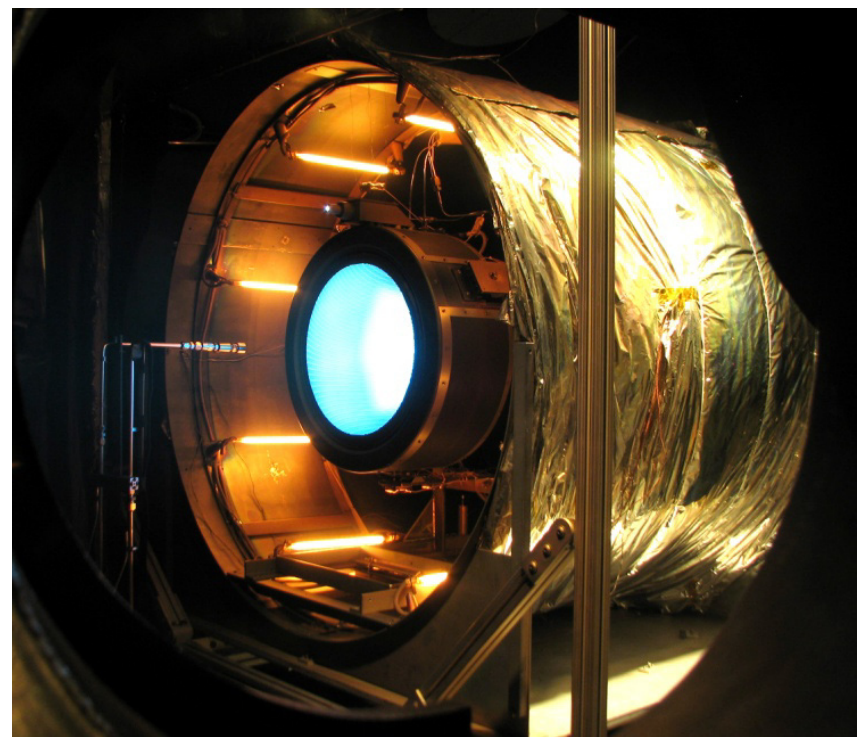

Figure 9 - NEXT thermal vacuum testing at JPL.

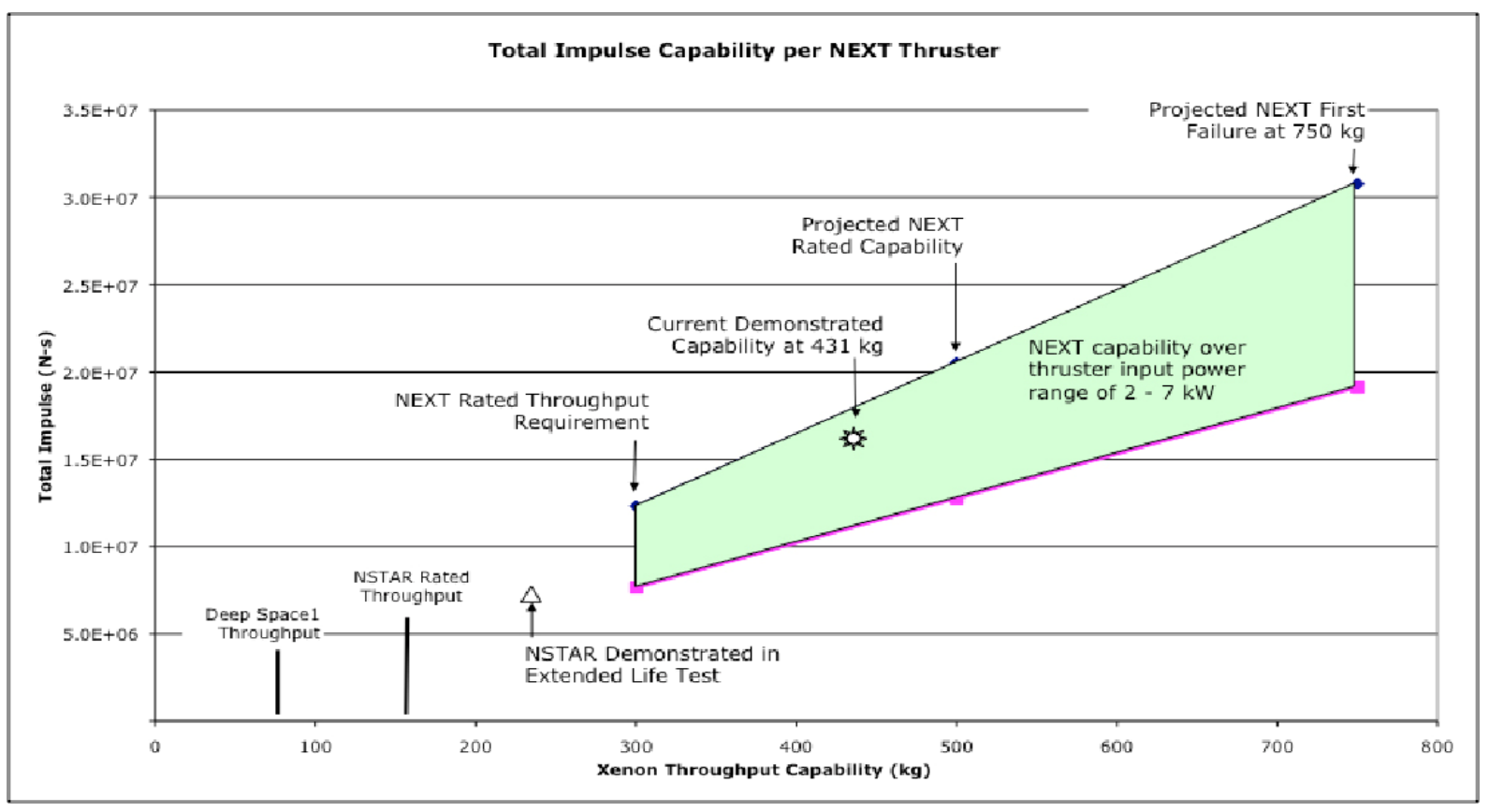

Figure 10 - Next Thruster Total Impulse Capability 
In addition to the thruster, the system includes a powerprocessing unit (PPU). The PPU contains all the electronics to convert spacecraft power to the voltages and currents necessary to operate the thruster (Figure 11). Six different power supplies are required to start and run the thruster with voltages reaching $1800 \mathrm{VDC}$ and total power processing at $7 \mathrm{~kW}$. L3 Communications designed and fabricated the NEXT Engineering Model (EM) PPU. After completing acceptance tests, the PPU was incorporated into the singlestring integrated test. Environmental testing follows including electromagnetic interference/electromagnetic compatibility (EMI/EMC) testing to characterize the capability and emissions of the unit.

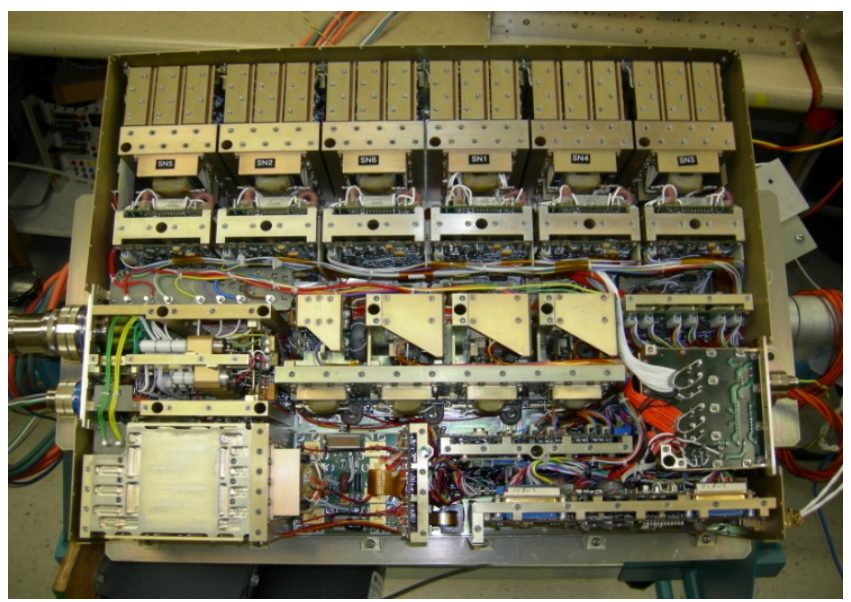

Figure 11 - NEXT Engineering Model PPU

A xenon feed system was developed (Figure 12), and is comprised of a single high-pressure assembly (HPA) with multiple low-pressure assemblies (LPA). The HPA regulates xenon flow from tank pressure to a controlled input pressure to the LPAs. Each LPA provides precise xenon flow control to the thruster main plenum, discharge cathode, or neutralizer cathode. The entire system constitutes the propellant management system (PMS). PMS development is complete and the system passed all performance and environmental objectives. The system is single fault tolerant, 50 percent lighter than the Dawn xenon feed system, and can regulate xenon flow to the various components to better than three percent accuracy.

An engineering-model (EM) fidelity gimbal mechanism was developed that can articulate the thruster approximately 18 degrees in pitch and yaw (Figure 13). The NEXT project team successfully demonstrated performance of the EM gimbal. The gimbal sub-system incorporates a design that improves specific mass over the Dawn gimbal. The gimbal was mated with the thruster, and successfully completed vibration testing first with a mass simulator and then with the NEXT PM thruster.

The project team completed development of the digital control interface unit (DCIU) simulator. This allows communication and control of all system components during testing. A flight DCIU is the interface between the ion propulsion system and the spacecraft. Life models, system level tests, such as a multi-thruster plume interaction test, and various other supporting tests and activities are part of recent NEXT system developments. JPL, Aerojet and L3 Communications are providing major support for the project.
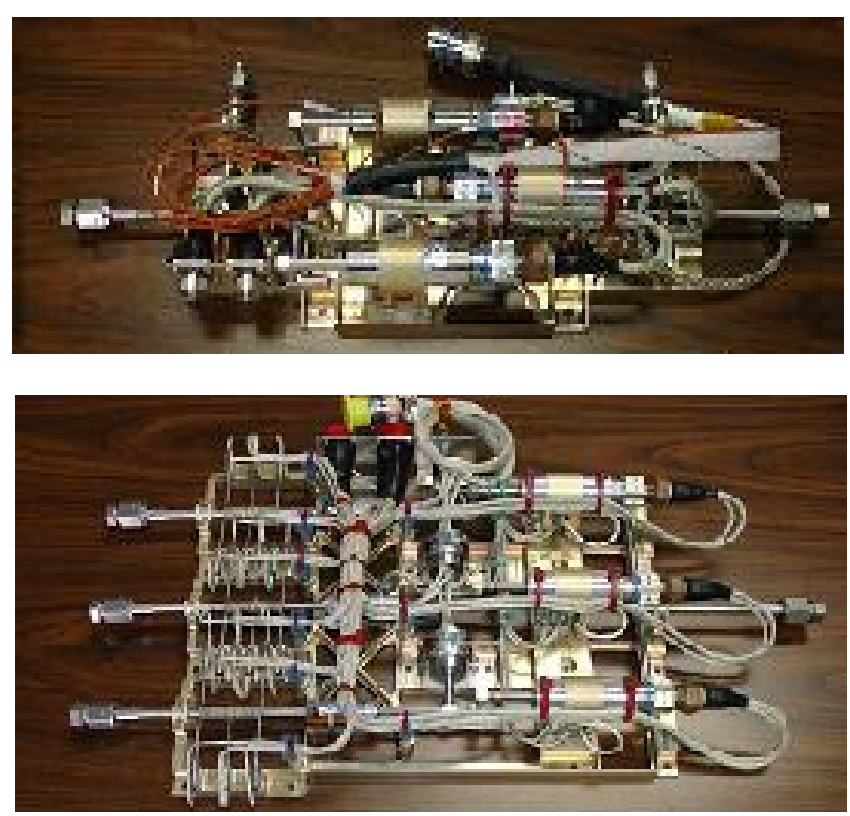

Figure 12 - NEXT Xenon Feed system High and Low Pressure Assemblies

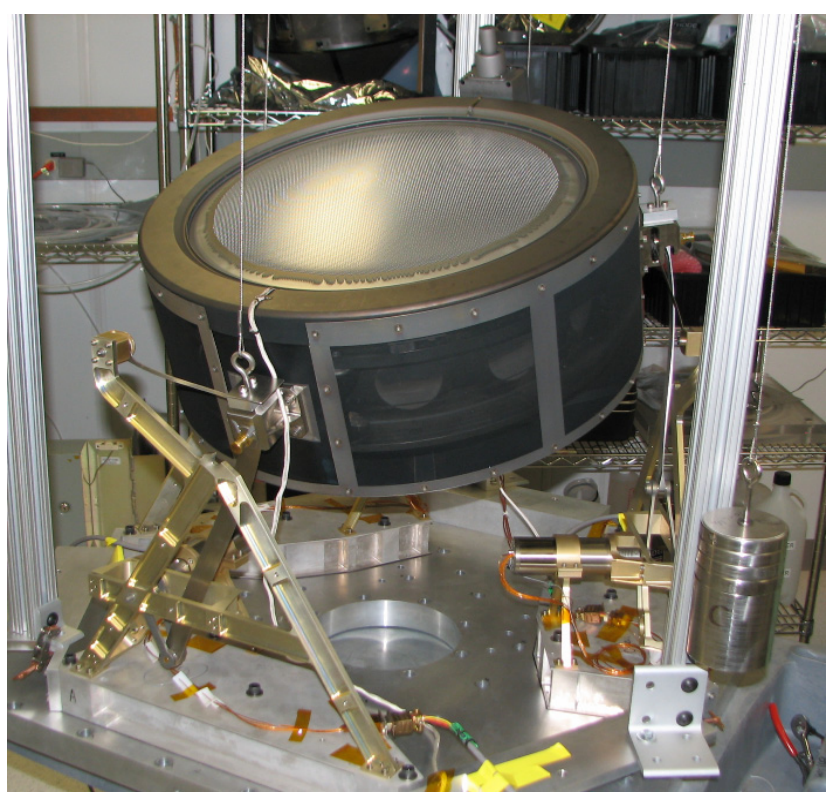

Figure 13 - NEXT Thruster and Gimbal Mechanism

The integrated NEXT system was tested in relevant space conditions as a complete string. With the exception of the PPU environmental tests, this brings the system to a TRL level of 6 and makes it a candidate for all upcoming mission opportunities. The life test demonstrated sufficient throughput for many science destinations of interest. The 
test plan is to continue into the coming years validating greater total impulse capability with the aim of demonstrating $750 \mathrm{~kg}$ of xenon throughput. Additional information on the NEXT system can be found in the NEXT Ion Propulsion System Information Summary in the New Frontiers and Discovery program libraries. [3,8,27]

NASA's In-Space Propulsion Technology project is investing in the Advanced Xenon Feed System (AXFS) for electric propulsion systems. The feed system is designed for an increased reliability with decrease in system mass, volume, and cost of SOA flight systems and comparable TRL 6 technology. The final development module, the pressure control module (PCM), was completed in 2007. The NRL completed functional and environmental testing of the VACCO PCM in September of 2008. Following the environmental testing, the PCM was integrated with the FCMs and an integrated AXFS with controller was delivered to the project. NASA GRC completed hot-fire testing of the AXFS (Figure 14) with the HIVHAC Hall thruster successfully demonstrating hot-fire operation using closed-loop control with downstream pressure feedback and with the Hall thruster discharge current. Follow-on testing determines the viability of the AXFS to perform singlestage, single module, control from high-pressure xenon directly to a thruster.

The AXFS technology is ready for transition into a qualification program. It achieved its objective[10] by demonstrating accurate xenon control with significant system reduction in mass and volume through the use of integrated modules for low-cost control options and/or reliability beyond practical SOA technology implementation. The resultant feed system represents a dramatic improvement over the NSTAR flight feed system and represents an additional 70 percent reduction in mass, 50 percent reduction in footprint, and 50 percent reduction in cost over the baseline NEXT feed system at TRL 6 . The project successfully completed the integrated system testing and advanced the modules to TRL 6.[10]

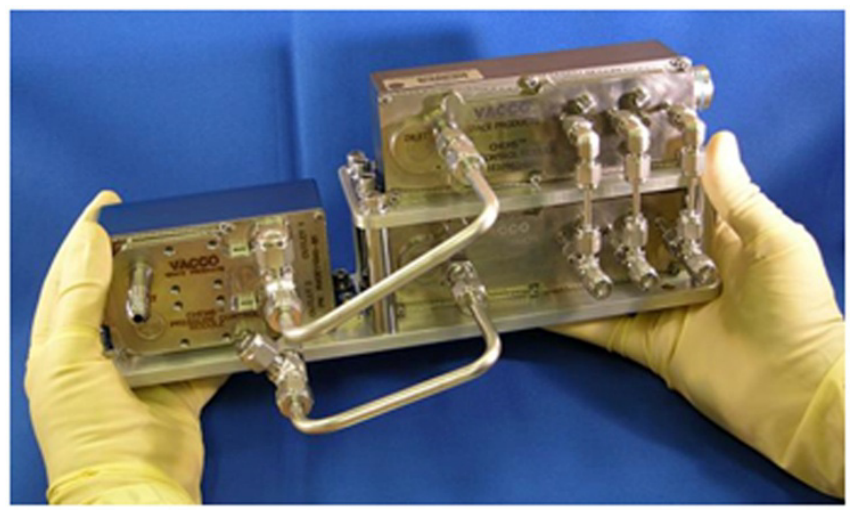

Figure 14 - AXFS mounted in hot-fire configuration.

In order to reduce costs for NASA science mission and leverage recent feed system flight experiences, JPL has developed a standard architecture for electric propulsion systems. One task under development is the maturation of the Digital Control Interface Unit (DCIU). The brassboard DCIU was designed and fabricated as shown in Figure 15. The unit is undergoing functionality tests with flight software routines and operated with resistive loads. The feed system design approach is valid for either Hall or ion thruster systems and can utilize either commercial or NASA-specific components. Critical components of the simplified feed system were obtained for a demonstration test performed with an NSTAR-like laboratory-ion thruster. A single-string feed system was assembled using flight-like components consisting of a mechanical regulator and the proportional flow control valves, pressure transducers, and flow control devices necessary for a low-pressure assembly. The tests demonstrated operation over a representative throttle table and characterized system operation including flow stability and throttling performance.[11]

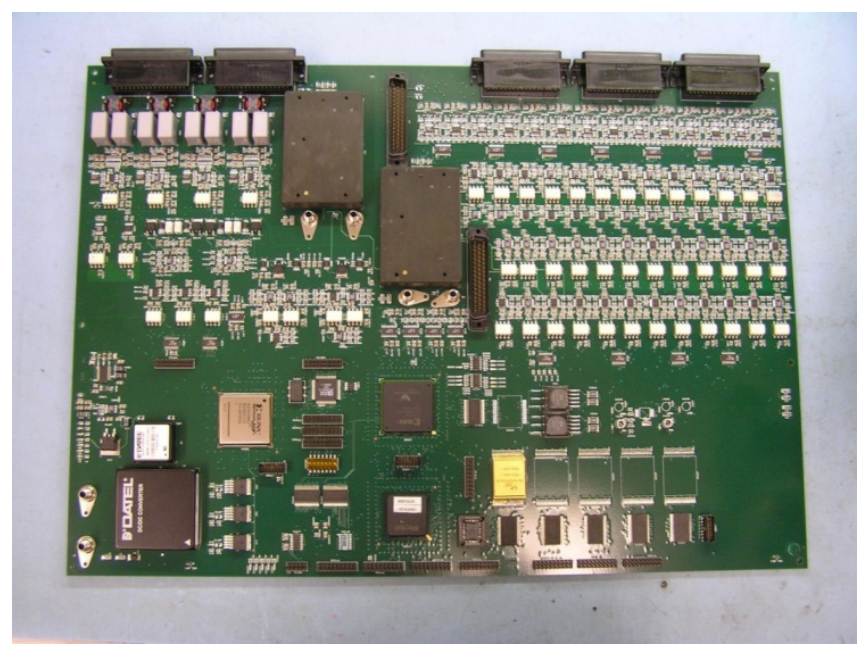

\section{Figure 15 - Standard Architecture Brassboard DCIU.}

In the original solicitation, NEXT was selected as an electric propulsion system for flagship missions. NEXT is the most capable electric propulsion system ever developed. A single NEXT thruster:

- uses seven kilowatts of power,

- has an estimated propellant throughput capability of over $750 \mathrm{~kg}$,

- has a lifetime of over 35,000 hours of full power operation,

- has a total impulse capability of approximately 30 million N-s, or about three times that of the SOA DAWN thrusters.

This performance leads to benefits for a wide range of potential mission applications.

The NEXT thruster has clear mission advantages for very challenging missions. For example, the Dawn Discovery Mission only operates one NSTAR thruster at a time, but requires a second thruster for throughput capability. For the same mission, the NEXT thruster could deliver mass, 
equivalent to doubling the science package, with only a single thruster. Reducing the number of thrusters reduces propulsion system complexity and spacecraft integration challenges.

The missions that are improved through the use of the NEXT thruster are those requiring post-launch $\Delta \mathrm{V}$, such as sample returns, highly inclined, or deep-space body rendezvous missions. The comet sample return mission was studied for several destinations because of its high priority within the New Frontiers mission category. In many cases, chemical propulsion was considered infeasible due to launch vehicle limitations. Specifically for Temple 1 in Ref. [1213], the NSTAR thruster was able to complete the mission, but required large solar arrays and four or five thrusters to deliver the required payload. NEXT would be able to deliver 10 percent more total mass and require half the number of thrusters.

NEXT can not only deliver larger payloads, but can reduce trip times and increase launch window flexibility. Chemical options exist for several missions of interest. However, the large payload requirements of flagship missions often require multiple gravity assists that both increase trip time and decrease the launch opportunities. In the recent Enceladus flagship mission study, the NEXT SEP option was able to deliver comparable payloads as the chemical alternative using a single Earth gravity assist. The chemical option for Enceladus required a Venus-Venus-Earth-Earth gravity-assist. This adds thermal requirements and increased the trip time by 57 months, from 7.5 to 12.25 years.

The ISPT portfolio of the NEXT system, HIVHAC thruster, and subsystem improvements offer electric propulsion solutions for scientific missions previously unattainable. The systems are compatible with spacecraft designs that can inherently provide power for additional science instruments and faster data transfer rates. Scientists can open their options to highly inclined regions of space, sample return or multi-orbiter missions, or even deep-space rendezvous missions with more science and reduced trip times.

\section{SAMple Return Propulsion}

ISPT is investing in Sample Return Propulsion technologies for applications such as Earth-Return Vehicles for large and small bodies. The first example leverages the development of a High-Voltage Hall Accelerator (HIVHAC) Hall thruster into a lower-cost electric propulsion systems.[9] HIVHAC is the first NASA electric propulsion thruster specifically designed as a low-cost electric propulsion option. It targets Discovery and New Frontiers missions and smaller mission classes. The HIVHAC thruster does not provide as high a maximum specific impulse as NEXT, but the higher thrustto-power and lower power requirements are suited for the demands of some Discovery-class missions. Advancements in the HIVHAC thruster include a large throttle range from $0.3-3.5 \mathrm{~kW}$ allowing for a low power operation. It results in the potential for smaller solar arrays at cost savings, and a long-life capability to allow for greater total impulse with fewer thrusters. It allows for cost benefits with less complex systems.

Wear tests of the NASA-103M.XL thruster validated and demonstrated the patented life extending innovation as a means to mitigate discharge channel erosion as a life limiting mechanism in Hall thrusters. Test priorities focused on the wear test of the laboratory thruster to validate the lifetime extending innovation to demonstrate throughput capabilities of the design. The thruster, shown in Figure 16, operated in excess of 4700 hours $(100 \mathrm{~kg}$ of xenon throughput). Components for two EM thrusters were fabricated. To date only one thruster is assembled for tests. Preliminary performance mapping of the EM thruster at various operating conditions was performed at NASA GRC as shown in Figure 17. The test sequence will include performance acceptance tests, environmental tests and a long duration test in FY09/10. Given sufficient funding, the system could reach TRL 6 by 2010. Current plans include the design, fabrication and assembly of a full Hall propulsion system, but are pending final approval to proceed.

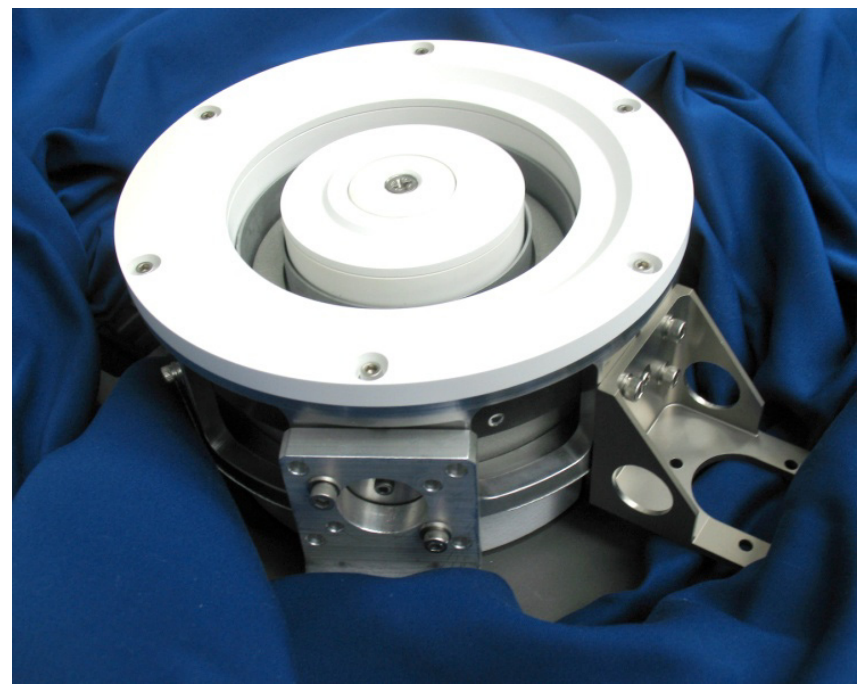

Figure 16 - HIVHAC Thruster Engineering Model

In addition to the thruster development, the HIVHAC project is evaluating PPU and xenon feed system XFS developments options that were sponsored by other projects but can apply directly to a HIVHAC system. The goal is to advance the TRL level of a HIVHAC Hall thruster propulsion system to level 6 in preparation for a first flight.

The functional requirements of a HIVHAC PPU are operation over a power throttling range of 300 to $3,800 \mathrm{~W}$, over a range of output voltages between 200 and $700 \mathrm{~V}$, and output currents between 1.4 and $5 \mathrm{~A}$ as the input varies over a range of 80 to $160 \mathrm{~V}$. A Performance map across these demanding conditions was generated for one candidate option as shown in Figure 18. Beyond conventional feed system options, one option for feed systems that was 
demonstrated with the Hall thruster is the VACCO advanced xenon feed system.

The ISPT project addresses the need for low-cost electric propulsion options. Studies[13] indicate that a low-power Hall thruster is cost enabling, and enhances performance. Initial studies compared the HIVHAC thruster to SOA systems for Near-Earth Object (NEO) sample returns, comet rendezvous, and the Dawn science mission. The HIVHAC thruster is expected to have both a greater throughput capability and a lower recurring cost than the SOA NSTAR thruster.

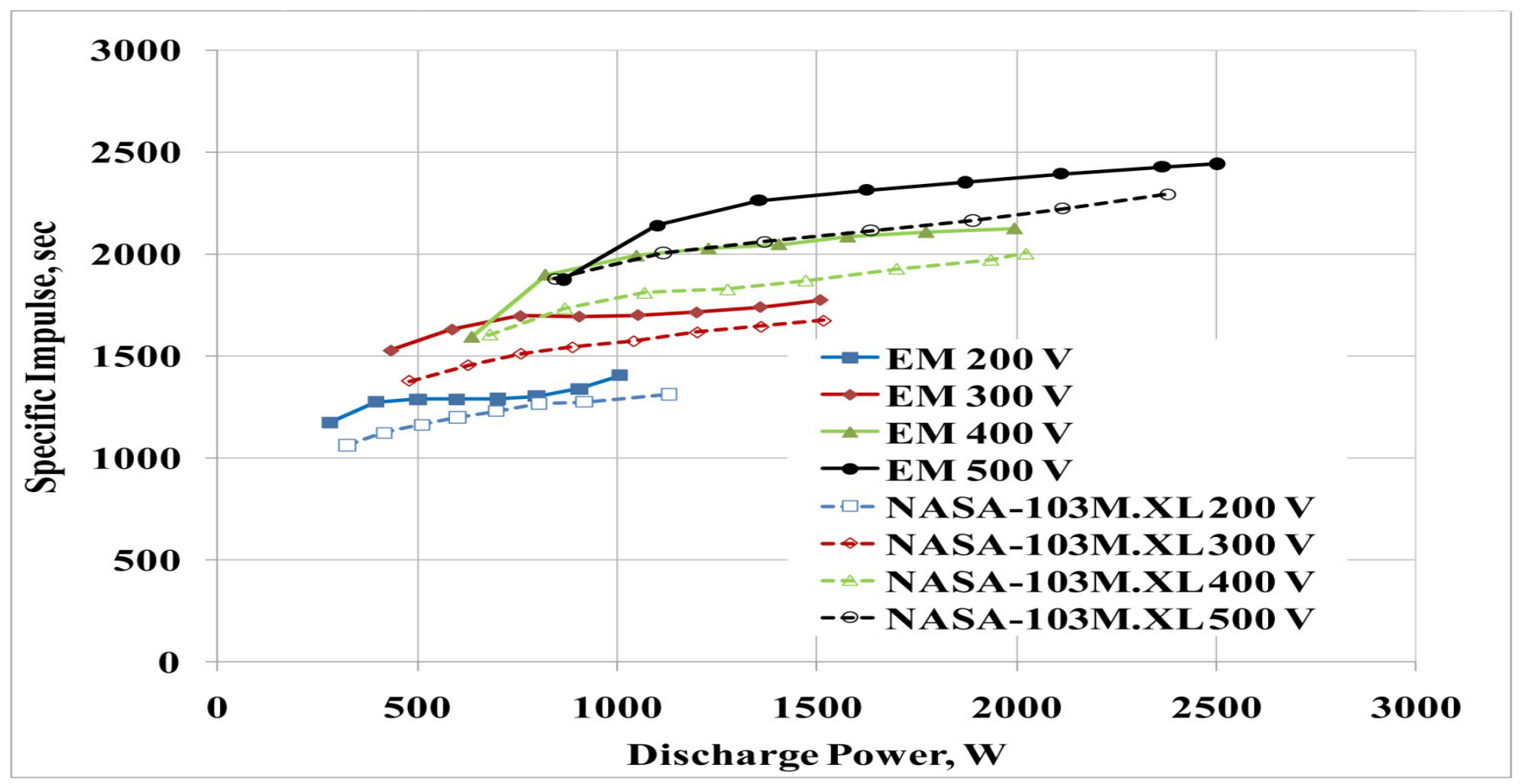

Figure 17 - Discharge specific impulse results for the HIVHAC EM-1 and NASA-103M.XL thrusters.

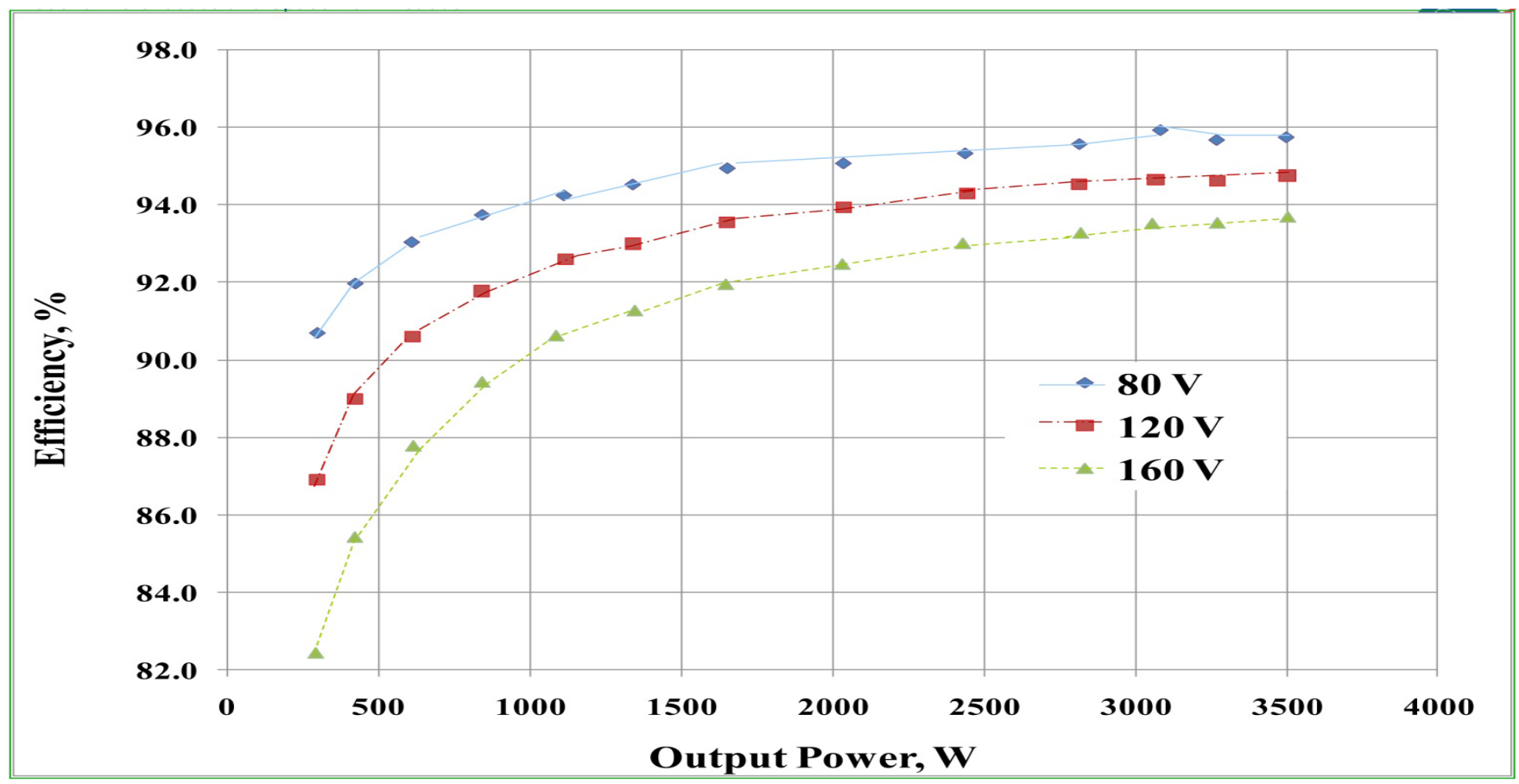

Figure 18 - Discharge power supply module efficiency at various input voltages 
For the NEO mission evaluated, the HIVHAC thruster system delivered over 30 percent more mass than the NSTAR system. The performance increase accompanied a cost savings of approximately 25 percent over the SOA NSTAR system. The Dawn mission was evaluated, and the expected HIVHAC Hall thruster delivered approximately 14 percent more mass at substantially lower cost than SOA, or decreasing the solar array provided equivalent performance at even greater mission cost savings.[14]

\section{Planetary ascent Vehicle}

For many years, NASA and the science community asked for a Mars Sample Return (MSR) mission. There were numerous studies to evaluate MSR mission architectures, technology needs and development plans, and top-level requirements. Because of the challenges, technologically and financially, of the MSR mission, NASA initiated a study to look at MSR propulsion technologies through the In-Space Propulsion Technology (ISPT) project office.[25] The objective of the ISPT project is to develop propulsion technologies that enhance or enable NASA science missions for the planetary science division by increasing performance while reducing cost, risk, and/or trip length. The largest propulsion risk element of the MSR mission is the Mars Ascent Vehicle (MAV).

The development of a major subsystem of the Mars Sample Return mission requires a direct and in-depth analysis on technology sensitivities to the overall MSR architecture and the mission's concept of operations (CONOPS). The MSR architecture dictates the physical and thermal environments, power requirements, and system interface of the MAV system.

The current architecture for the MSR lander is to use the Mars Science Laboratory (MSL) entry, descent, and landing (EDL) system. The MSL EDL requires minor modifications such as. a larger parachute, additional propellant, and COPV propellant tanks to accommodate for a lander that will slightly exceed the lander mass of the MSL rover. Using the MSL sky crane concept places restrictions on the MAV system options. The lander system concept is shown in Figure19.

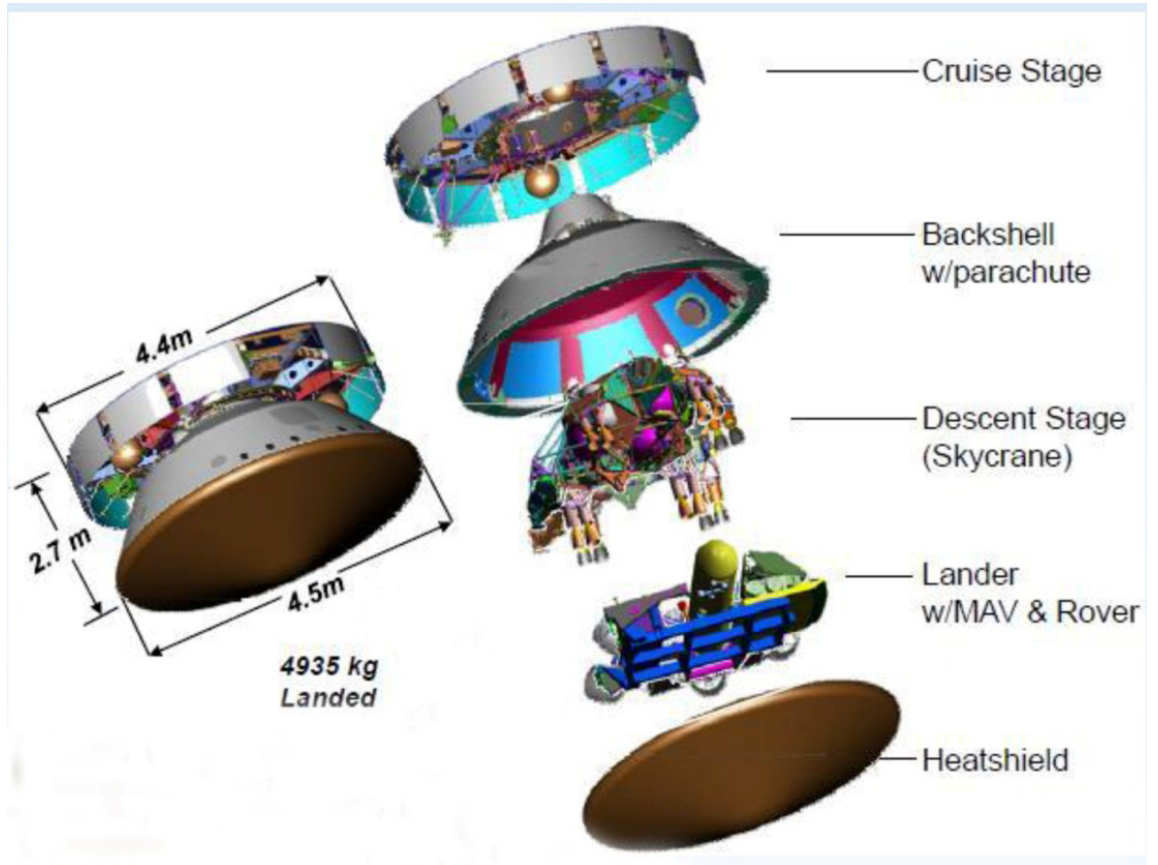

Figure 19 - Pre-decisional draft MAV lander system

Beyond the limitations of the EDL system, the MAV has specific requirements to deliver the orbiting sample (OS) in an orbit suitable for the Earth Return Vehicle (ERV). The basic requirements include:

- $500 \mathrm{~km}+/-100 \mathrm{~km}$ circular orbit

- + /- $0.2^{\circ}$ inclination

- Ability to launch from $+/-30^{\circ}$ latitudes

- Accommodate $\sim 5 \mathrm{~kg}, 16 \mathrm{~cm}$ diameter payload

- Continuous telemetry

- Storage for 90 Sols, potentially up to one year
The following technology development strategy is predecisional and is an approach under consideration. The strategy for technology development is the employment of an Integrated Product Development Team (IPDT) with updates as necessary to a technology steering community and host workshops as appropriate. The IPDT consists of members from ISPT project office, the Mars Exploration Program at JPL for intimate knowledge of the system interfaces, requirements, and sensitivities to the overall MSR mission, and NASA launch vehicle system design and test support. Management of the subsystem and system development is based in NASA's ISPT project with lead 
systems engineering support to maintain interface controls and guide system integration activities.

It is recommended that the initial tasks clearly define the requirements of component technology and calculate the potential return on investment. The definition of component level requirements and interfaces, and potential payoff are conducted through detailed collaborative engineering design, such as. JPL Team X, studies. It is anticipated that the component level developments would be competed; through the NASA Research Announcement (NRA) process.
Information was solicited in December 2008 - January 2009 for enhancing and enabling technologies for the Mars Ascent Vehicle. A task with The Aerospace Corporation was initiated in January of 2009 to investigate military technology applicability to the MAV. The responses and results were evaluated, ranked, and used to develop text for a potential NRA solicitation. A top-level assessment of technology options, risk and predicted mass performance are shown in Figure 20. Some of the proposed technologies have potential to converge within the existing MSL EDL capabilities while other options may be enabled by enhancements to the EDL system.

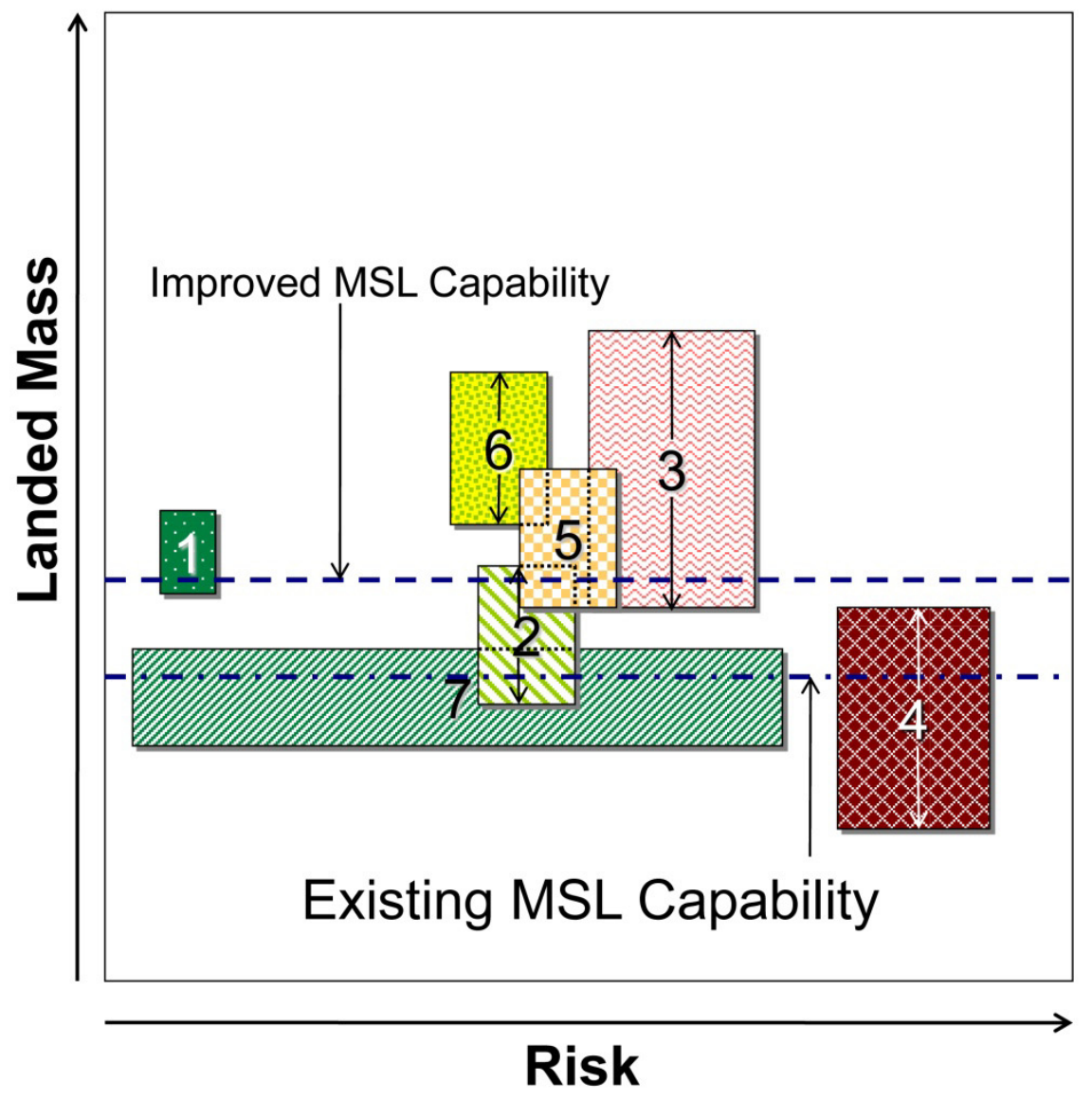

Propulsion Options

1) Two-stage solid

2) Single stage pumpfed bipropellant

3) Gel bipropellant

4) Exotic propellants

5) $1^{\text {st }}$ stage solid, $2^{\text {nd }}$ stage bipropellant

6) Two-stage bipropellant

7) Advanced Concept

Figure 20 - Assessment of MAV technology options.

During the completion of technology component level development, and the propulsion system advancement to TRL 6, a system integrator will have a key role in guiding investments towards an integrated system for system level demonstrations and possible flight tests.

\section{Multi-Mission EARTh Entry Vehicle}

The Earth Entry Vehicle (EEV), that returns the Mars samples to our planet's surface, needs to be extremely reliable to meet the integrated probability of release goal of one in a million during any part of the atmospheric entry or surface impact. The EEV travels to Mars connected to the
Orbiter/Earth Return Vehicle, waits for insertion of the Orbiting Sample, travels back to Earth as part of the Earth Return Vehicle (ERV), then is released and targeted for Earth impact. The EEV provides the thermal and acceleration environments necessary to maintain the samples for maximum scientific return.

Detailed studies show that to meet the stringent containment requirements of the mission, the Earth Entry Vehicle should possess particular design attributes. First, the vehicle must be "self-righting," so it will quickly stabilize itself in a heatshield-forward orientation if the release from the ERV, a micrometeoroid impact, or some other anomaly, cause it to 
enter the atmosphere in any other orientation. Second, the TPS of the heat shield needs to be robust enough to ensure a high level of reliability. Third, the EEV has no parachute or other deployable drag device, since the reliability of such a device is much less than required (the capsule needs to be designed to take an Earth impact load in the event of a failure of the drag device).

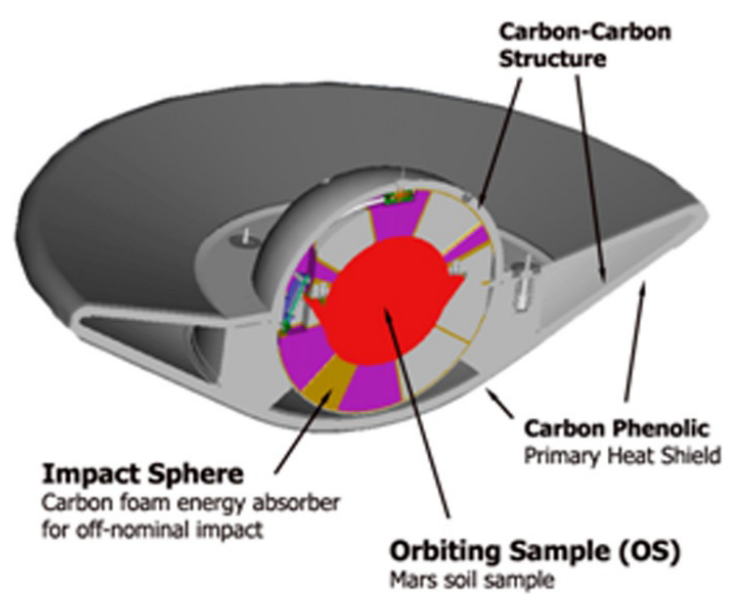

Figure 21. NASA's current EEV design.

In the 2000 timeframe, NASA teams developed a detailed conceptual design of the MSR Earth Entry Vehicle. This design was supported by wind tunnel and impact testing, and is seen in Figure 21. The main features were a CarbonCarbon structure, carbon foam impact absorption, a particular aftbody shape shown to be self-righting, and a carbon phenolic heatshield. The basic design is still valid today, but needs to be updated for any new mission requirements (such as sample mass, Orbiting Sample size, contamination mitigation strategy, temperature, and impact load). The design would benefit from materials and process improvements from the last ten years. All of the component technologies are available today, with the exception of the carbon phenolic heatshield material. The United States has almost no supply of the heritage rayon used to make the historical carbon phenolic, which flew thousands of times in military applications and which forms the basis for the high reliability required for MSR. Rayon processes changed and the carbon phenolic made from new rayon has to be proven equivalent to the heritage material. New heatshield materials available today may be considered for their micrometeoroid tolerance. The current EEV design requires rigorous ground testing to ensure reliability, and construction of an Engineering Development Unit to validate systems engineering.

Detailed development schedules and costs were developed for the EEV. Within the development path, there are no lowTRL components or extreme risk items. The biggest challenge is to adequately prove the reliability of the components and the system. The current estimate to develop the EEV technology to TRL6 is approximately \$41 million.
This does not include a dedicated flight test, which many experts agree is needed to achieve the one-in-a-million system reliability, since the entry flight environment cannot be replicated in ground-based facilities. This is a fairly expensive flight test due to the high entry velocities that are required. One way to achieve a flight validation for little extra cost to NASA is to use the MSR EEV design, or at least the major components of the design, to return samples from another mission like New Frontiers or Discovery. NASA Headquarters managers and the In-Space Propulsion Technology (ISPT) team are pursuing this approach, but currently there are no manifested missions that are planning to use an MSR EEV design.

\section{SySTEMS/MisSION ANALYSIS}

Systems analysis is used during all phases of any propulsion hardware development. The systems analysis area serves two primary functions:

1. to help define the requirements for new technology development and the figures of merit to prioritize the return on investment,

2. to develop new tools to easily and accurately determine the mission benefits of new propulsion technologies allowing a more rapid infusion of the propulsion products.

Systems analysis is critical prior to investing in technology development. In today's environment, advanced technology must maintain its relevance through mission pull. Current systems analysis tasks include Radioisotope Electric Propulsion (REP) system requirements, lifetime qualification of gridded-ion and Hall thrusters, active mixture ratio control, and the evaluation of commercial electric propulsion systems for possible application to science mission needs.

The second focus of the systems analysis project area is the development and maintenance of tools for the mission and systems analyses. Improved and updated tools are critical to clearly understand and quantify mission and system level impacts of advanced propulsion technologies. Having a common set of tools increases confidence in the benefit of ISPT products both for mission planners as well as for potential proposal reviewers. Tool development efforts were completed on the Low-Thrust Trajectory Tool (LTTT) and the Advanced Chemical Propulsion System (ACPS) tool.

Low-thrust trajectory analyses are critical to the infusion of new electric propulsion technology. Low-thrust trajectory analysis is typically more complex than chemical propulsion solutions. It requires expertise to evaluate mission performance. Some of the heritage tools proved to be extremely valuable, but cannot perform direct optimization and require good initial guesses by the users. This leads to solutions difficult to verify quickly and independently. The ability to calculate the performance benefit of complex 
electric propulsion missions are intrinsic to the determination of propulsion system requirements. The ISPT office invested in multiple low-thrust trajectory tools that independently verify low thrust trajectories at various degrees of fidelity.

The ISPT low-thrust trajectory tools suite includes Mystic, the Mission Analysis Low Thrust Optimization (MALTO) program, Copernicus, and Simulated N-body Analysis Program (SNAP). SNAP is a high fidelity propagator. MALTO is a medium fidelity tool for trajectory analysis and mission design. Copernicus is suitable for both low and high fidelity analyses as a generalized spacecraft trajectory design and optimization program. Mystic is a high fidelity tool capable of N-body analysis and is the primary tool used for trajectory design, analysis, and operations of the Dawn mission. While some of the tools are export controlled, the ISPT website does offer publicly available tools and includes instructions to request tools with limited distribution. The ISPT project team is planning a series of courses for training on the ISPT project tools.

The ability for the user community to rapidly and accurately access the mission level impacts of ISPT products can ease technology infusion. In addition to the tools currently available, there are on-going activities to develop an Aerocapture Quicklook tool to allow users an opportunity to quantify mission benefits of an aerocapture system including mass properties and geometry. Every effort will be made to have these tools validated, verified, and made publicly available. Instructions to obtain the tools currently available are provided on the ISPT project website: http://spaceflightsystems.grc.nasa.gov/Advanced/SciencePr oject/ISPT/

\section{TECHNOLOGY INFUSION}

The ISPT project is developing several technologies that have reached TRL 6 and are potentially applicable for infusion into future, Flagship, New Frontiers, and Discovery mission opportunities. Three technologies in particular are the NASA's Evolutionary Xenon Thruster (NEXT) ion propulsion system, the Advanced Material Bi-propellant Rocket (AMBR) engine, and Aerocapture. ISPT and NASA are exploring several different paths to get its technology investments infused into future NASA, DOD, or commercial missions.

NASA recognizes that it is desirable to fly new technologies that enable new scientific investigations or to enhance an investigation's science return. The SSE Roadmap states that NASA will strive to maximize the payoff from its technology investments, either by enabling individual missions or by enhancing classes of missions with creative solutions. Discovery, New Frontiers, and Flagship missions potentially provide opportunities to infuse advanced technologies developed by NASA, and advance NASA's technology base and enable a broader set of future missions. To benefit from its technology investments, NASA provided an incentive to encourage the infusion of NEXT ion propulsion system or the AMBR engine into mission proposals in response to the New Frontiers 3 Announcement of Opportunity (AO). NASA is also considering offering an incentive to encourage the infusion of NEXT ion propulsion system, the AMBR engine, or aerocapture into mission proposals in response to the upcoming Discovery 2010 Announcement of Opportunity (AO). The Discovery 2010 draft AO was out for community comment at the time this paper was written, and the final aspects of the technology incentives had not been finalized. Under these AO's, proposers are offered an option of adopting one of the specific technologies for insertion into their missions. NASA would then share in the flight development costs of the proposed advanced technology, up to certain amounts specified in the AO depending upon which technology is proposed.

Beyond the New Frontiers opportunity, ISPT continues to seek opportunities to infuse NEXT, AMBR, Aerocapture, and its other technologies into a wide range of possible future mission opportunities. The ISPT project office and NEXT team personnel are actively supporting various flagship science definition team (SDT) studies such as those for Venus and outer planet flagship missions looking at Enceladus or the Titan-Saturn system. The Titan-Saturn System Mission study, a JPL-led Outer Planets Flagship mission concept study, baselined a NEXT-based SEP system to provide the mass required to accomplish the desired science mission objectives. This was an SMDdirected and funded pre-phase A study. The Comet-Surface Sample Return Mission study, an APL led New Frontiersclass mission concept study, recommended a NEXT-based SEP mission as a preferred approach over a chemical propulsion mission concept. This was an SMD-directed and funded pre-phase A study. The New Worlds Observer Mission concept study baselined a NEXT-based SEP system to provide the capability required to accomplish the desired exoplanet detection and characterization science objectives. This is a pre-phase A study, which was awarded under the SMD Astrophysics Strategic Mission Concept Studies NRA. The NEXT team supported APL on the Solar Probe mission. ISPT personnel supported several white papers that were developed in response to the current decadal survey development activities in 2009/2010. ISPT contributed to identifying the technology development that is required to accomplish the future missions being contemplated.

\section{Conclusion And Future Plans}

Known future missions of interest for NASA and the science community, and those which are yet to be conceived, continue to demand propulsion systems with increasing performance and lower cost. This paper addressed how the ISPT project is developing propulsion technologies for NASA missions to address this demand. ISPT completes current developments to TRL 6 in the next year, and continues to support possible infusion. Among these is the NEXT electric propulsion system, which wraps- 
up PPU development and testing in 2010, but continues long-duration life testing for several more years. The NEXT system is available for all future mission opportunities. The AMBR engine reached TRL 6 with the completed development of the high temperature bi-propellant chemical thruster in 2009, and wraps-up the final reporting and documentation in early 2010. Finally, an aerocapture system comprised of a blunt body TPS system, the GN\&C, sensors and the supporting models is to achieve its technology readiness by mid 2010 . Regardless, if the mission requires electric propulsion, aerocapture, or a conventional chemical system, ISPT technology has the potential to provide significant mission benefits including reduced cost, risk, and trip times, while increasing the overall science capability and mission performance. Aerocapture and electric propulsion are frequently identified as enabling or enhancing technologies.

ISPT continues to look for ways to reduce system level costs and enhance the infusion process. The cost of life testing of electric propulsion thrusters is one area where the savings are expected to be significant. Standardizing on common components or sub systems and utilizing modular stages for multiple missions is a way to reduce propulsion system costs. Performance enhancements tasks are anticipated in the area of electric propulsion through design and material improvements to achieve longer thruster life. Costs are addressed in the design process of the Hall thruster, and through modular design and shared hardware for NEXT and other electric propulsion systems. In the aerocapture area, the development plan for the rigid body aeroshell technologies follows a development plan proposed to the ST9 mission. In the chemical and component area, development in materials and engine designs continues to improve performance and reduce costs through advanced manufacturing techniques.

Future propulsion needs include an electric propulsion system that is powered by a radioisotope-powered generator. Current EP systems are designed for widely varying input power levels to account for the spacecraft's motion around the solar system. If the vehicle does not need to rely on solar power, then the propulsion system is simpler and lighter. The system can be optimized around a known constant input power.

The future focus areas for ISPT are propulsion systems for sample return missions. Activity in these technology development areas increases in 2010. The direction focuses on: 1) Planetary Ascent Vehicles (PAV); 2) multi-mission technologies for Earth Entry Vehicles (MMEEV) needed for sample return missions; and 3) electric and chemical propulsion for Earth Return Vehicles (ERV), transfer stages, and low cost Discovery-class missions. These sample return missions are inherently propulsion intensive. Several of the ISPT technology areas may be involved in a single sample return mission. The mission may use EP for transfer to, and possibly back from, the destination. Chemical propulsion utilized for the ascent and descent to the surface. Aeroshells used for Earth re-entry and an aerocapture maneuver used to capture at the destination. Studies in the three focus areas continue, and technology development activities are progressing. While the budget is tight for the next few years, the future is bright for ISPT.

\section{REFERENCES}

[1]"2006 Solar System Exploration Roadmap for NASA's Science Mission Directorate," September 2006.

[2]Anderson, D. J. et. al., “The NASA In-Space Propulsion Technology Project, Products, and Mission Applicability," 2009 IEEE Aerospace conference, March 2009, Paper \#1176.

[3]New Frontiers Program Library, URL: http://newfrontiers.larc.nasa.gov/NFPL.html

[4]"Advanced Material Bi-propellant Rocket (AMBR) Information Summary August 2008," New Frontiers Program Library,

[5]Portz, R., Krismer, D., Lu, F., and Miller, S., "High Pressure Bipropellant Engine System Study," AIAA2007-5433 42nd AIAA/ASME/SAE/ASEE Joint Propulsion Conference and Exhibit, Sacramento, CA, July, 2006.

[6]Patterson, M. and Benson, S., "NEXT Ion Propulsion System Development Status and Performance", AIAA2007-5199, 43rd AIAA/ASME/SAE/ASEE Joint Propulsion Conference and Exhibit, Cincinnati, OH, July 2007

[7]Benson, S., Patterson, M., et al., "NASA's Evolutionary Xenon Thruster (NEXT) Ion Propulsion Technology Development Status in 2009", IEPC-2009-150, 31st International Electric Propulsion Conference, Ann Arbor, MI, September 2009.

[8]"NASA's Evolutionary Xenon Thruster (NEXT) Ion Propulsion system Information Summary August 2008," New Frontiers Program Library, URL: http://newfrontiers.larc.nasa.gov/NFPL.html

[9]Kamhawi, H., "Overview of the High voltage Hall Accelerator Project," AIAA-2009-5282, 45th AIAA/ASME/SAE/ASEE Joint Propulsion Conference and Exhibit, Denver, CO, August 2009. 
[10]Dankanich, J. W., Cardin, J., Dien, A., Kamhawi, H., Netwall, C. J., and Osborn, M., "Advanced Xenon Feed System (AXFS) Development and Hot-fire Testing," 45th AIAA/ASME/SAE/ASEE Joint Propulsion Conference, Denver, CO, August 2-5, 2009.

[11]Snyder, J.S., Randolph, T.M., Hofer, R.R., and Goebel, D.M., "Simplified Ion Thruster Xenon Feed System for NASA Science Missions," IEPC 2009-064, 31st International Electric Propulsion Conference, Ann Arbor, MI, Sept. 2009.

[12]Oh, D., Benson, S., Witzberger, K., and Cupples, M., "Deep Space Mission Applications for NEXT: NASA's Evolutionary Xenon Thruster," AIAA-2004-3806, 40th AIAA/ASME/SAE/ASEE Joint Propulsion Conference and Exhibit, Fort Lauderdale, GL, July, 2004.

[13]Cupples, M., Coverstone, V., and Woo, B., “Applications of Solar Electric Propulsion to a Comet Surface Sample Return Mission," AIAA-2004-3804, 40th AIAA/ASME/SAE/ASEE Joint Propulsion Conference and Exhibit, Fort Lauderdale, GL, July, 2004.

[14]Oh, D.,"Evaluation of Solar Electric Propulsion Technologies for Discovery Class Missions," AIAA2005-4270, 41st AIAA/ASME/SAE/ASEE Joint Propulsion Conference \& Exhibit, Tucson, AZ, July, 2005.

[15]"March 2008 OPAG Meeting Report," Cited May 27, 2008, http://www.lpi.usra.edu/opag/

[16]Congdon, W. M., "Family Systems of Advanced Charring Ablators for Planetary Aerocapture and Entry Missions," 1st NSTC, University of Maryland, June 1921, 2007.

[17]Wright, M. J., Bose, D., and Olejniczak, J.,"The Effect of Flowfield-Radiation Coupling on Aeroheating for Titan Aerocapture", AIAA Paper No. 2004-0484, presented at the 42nd AIAA Aerospace Sciences Conference and Exhibit, Reno, Nevada, Jan. 2004.

[18]Wright, M. J.,Bose, D., and Chen, Y. K., "Probabilistic Modeling of Aerothermal and Thermal Protection Material Response Uncertainties," 53rd JANNAF Joint Propulsion Meeting, Dec. 2005.

[19]Willcockson, W. W., NASA Contractor Report (pending), "Final Summary Report: Aerocapture Aeroshell Technologies (AAT) Program," January 31, 2007.

[20]Miller, K. L. et al., NASA Contractor Report (pending), "Ultralight-weight Ballute Technology for Aerocapture and Aeroassist Missions,” January 2007.
[21]Reza, S., NASA Contractor Report (pending), "Aerocapture Inflatable Decelerator: Lockheed Martin Inflatable Aeroshell Final Report,” January 11, 2007.

[22]Lockwood, M. K.,et al., "Systems Analysis for a Venus Aerocapture Mission," NASA TM 2006-214291, March 2006.

[23]Lockwood, M. K., et al., "Aerocapture Systems Analysis for a Neptune Mission," NASA TM 2006-214300, April 2006 .

[24]Wright, H. S., et al., "Mars Aerocapture Systems Study," NASA TM 2006-214522, August 2006.

[25]Dankanich, J. W., "Mars Ascent Vehicle Technology Planning," 2009 IEEE Aerospace Conference, Big Sky, MT, March 2009.

[26]Liou, L.C., Dankanich, J.W., Alexander, L.,L., "NASA In-Space Advanced Chemical Propulsion Development in Recent Years," AIAA-2009-5126, 45th AIAA/ASME/SAE/ASEE Joint Propulsion Conference and Exhibit, Denver, CO, August 2009.

[27]Discovery Program Library, URL:

http://discovery.larc.nasa.gov/dpl.html

\section{BIOGRAPHY}

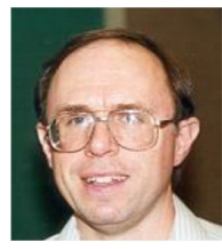

David Anderson is a project manager in the Science Project Office at the NASA Glenn Research Center (GRC). He is currently the Acting Project Manager for the In-Space Propulsion Technology (ISPT) project, and is the SBIR Spacecraft and Platform Subsystems Topic Manager. Formerly, he managed the advanced Radioisotope Power System (RPS) efforts at NASA GRC, was active with new business development and proposal development activities, and worked in GRC's Systems Management Office, where he was involved in project management oversight activities and led or was involved in several Center and NASA-wide program/project management process improvement teams or activities. He has a B.S. in Aerospace Engineering from the University of Cincinnati and an M.S. in Engineering Management from the Cleveland State University.

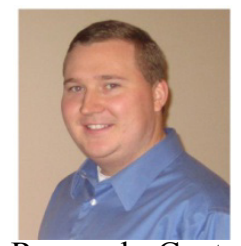

John Dankanich is a Gray Research contractor to the NASA Glenn Research Center. He is the electric propulsion lead systems engineer for the ISPT project. He also serves as a mission and systems analyst for the ISPT project and the Glenn Research Center. John has expertise is in mission and systems analyses, electric propulsion systems, and trajectory optimization. He supported propulsion system development, Mars ascent vehicle design, lunar lander guidance simulations, planetary defense studies, and 
advanced propulsion design and testing. John has a B.S. in Physics and Aerospace Engineering and an M.S. in Aerospace Engineering from Purdue University.

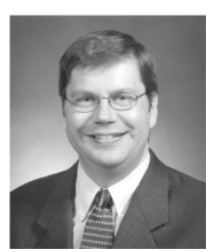

Eric Pencil is Propulsion Projects Area Manager for the In-Space Propulsion Technology Office at NASA Glenn Research Center. He is responsible for the management and execution of the electric propulsion development tasks for NASA Science missions. Previously he worked as a project/research engineer in the electric propulsion research group in which he worked on various electric propulsion technologies at varying stages of maturity from basic research to flight hardware.

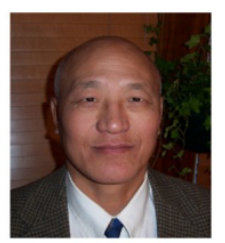

Larry Liou is a project manager for the advanced chemical propulsion area in the NASA In-Space Propulsion Technologies Project Office. Previously he performed research in liquid booster rocket engine combustion from 1988 to 1999 during which he evaluated various ignition concepts including laser ignition, and combustion wave ignition for the X-33 Aerospike engine. From 1999 to 2006 he served in various management positions at NASA John H. Glenn Research Center. Larry has a Bachelor of Science degree in mechanical engineering from University of Toledo and a Master's degree in thermal and fluids science from Case Institute of Technology.

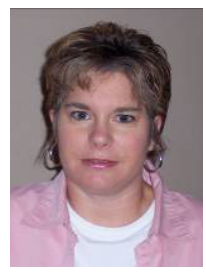

Michelle Munk has been a NASA employee for nearly 20 years, first at the Johnson Space Center, then at the Langley Research Center. She has been involved in Mars advanced mission studies for many years, both robotic and human, contributing interplanetary trajectory analysis and entry and descent analysis. She managed the delivery of International Space Station hardware, and was on the Mars Odyssey aerobraking operations team. In 2002, Ms. Munk accepted a detail assignment to become the Lead Engineer for Aerocapture Technology Development under In-Space Propulsion at Marshall Space Flight Center. She managed the technical work of ISP Aerocapture for nearly five years before becoming the Project Area Manager and returning to Langley in 2007. Ms. Munk is also involved in the Mars Science Laboratory Entry, Descent and Landing Instrumentation (MEDLI) project and contributes to other NASA projects developing entry system technologies. She has a BSAE from Virginia Tech and completed graduate coursework at the University of Houston. 